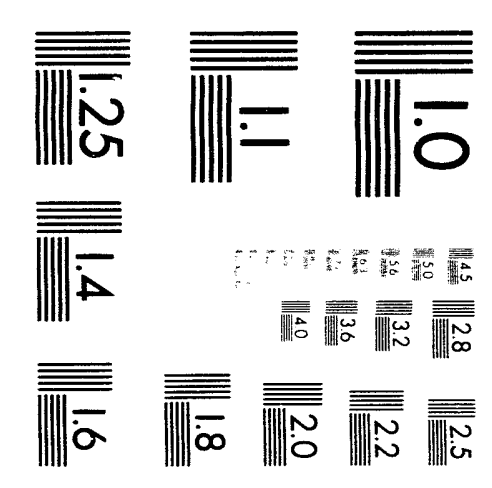



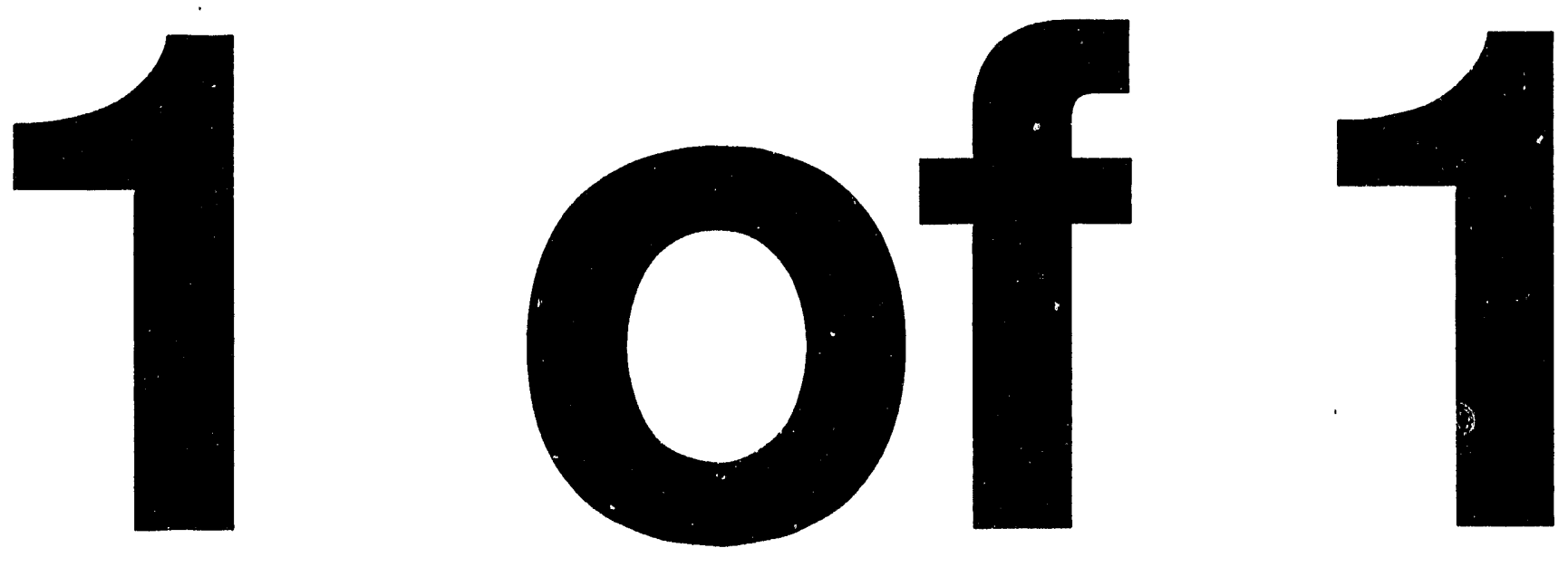
NUREG/CR-6059

SAND92-2146

\section{MACCS Version 1.5.11.1: A Maintenance Release of the Code}

Manuscript Completed: August 1993

Date Published: October 1993

Prcpared by

D. Chànin, ${ }^{1}$ J. Rollstin, ${ }^{2}$ J. Foster, ${ }^{1}$ L. Miller

Sandia National Laboratories

Albuquerque, NM 87185-5800

Prepared for

Division of Safety Issue Resolution

Office of Nuclear Regulatory Research

U.S. Nuclear Regulatory Commission

Washington, DC 20555-0001

NRC FIN A1853

1Technadyne Engineering Consultants, Inc.

Albuquerque, NM 87112

2GRAM, Inc.

Albuquerque, NM 87112 


\begin{abstract}
A new version of the MACCS code (version 1.5.11.1) has been developed by Sandia National Laboratories under sponsorship of the U.S. Nuclear Regulatory Commission. MACCS was del sloped to support evaluations of the off-site consequences from hypothetical severe accidents at commercial power plants. MACCS is the only current public domain code in the U.S. that embodies all of the following modeling capabilities: (1) weather sampling using a year of recorded weather data; (2) mitigative actions such as evacuation, sheltering, relocation, decontamination, and interdiction; (3) economic costs of mitigative actions; (4) cloudshine, groundshine, and inhalation pathways as well as food and water ingestion; (5) calculation of both individual and societal doses to various organs; and (6) calculation of both acute (nonstochastic) and latent (stochastic) health effects and risks of health effects. All of the consequence measures may be generated in the form of a complementary cumulative distribution function (CCDF).
\end{abstract}

The current version implements a revised cancer model consistent with recent reports such as BEIR V and ICRP 60 . In addition, a number of error corrections and portability enhancements have been implemented. This report describes only the changes made in creating the new version. Users of the code will need to obtain the code's original documentation, NUREG/CR-4691. 


\section{CONTENTS}

Section $\underline{\text { Page }}$

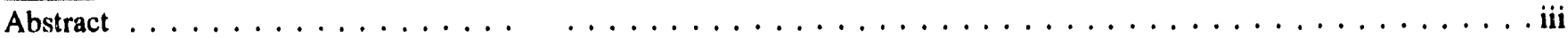

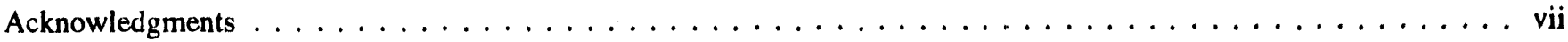

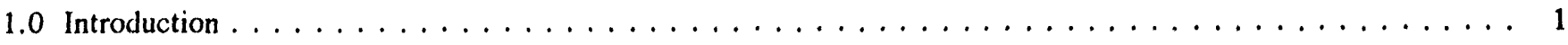

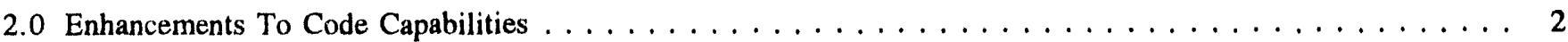

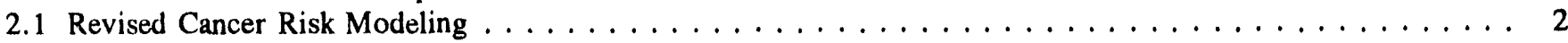

2.1.1 NRC Sponsored Review of Cancer Models Presented in LMF-132 . . . . . . . . . . . . . . . . . 3

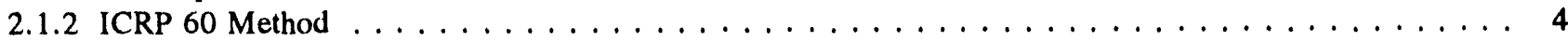

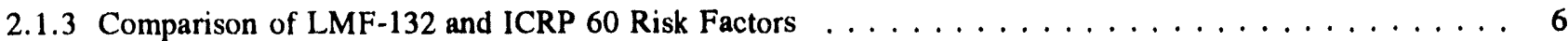

2.1.4 Cancer Risk From Combined High-LET and Low-LET . . . . . . . . . . . . . . . . . 6

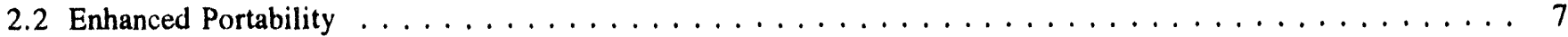

2.2 .1 Porting MACCS to VAX and UNIX Systems $\ldots \ldots \ldots \ldots \ldots$

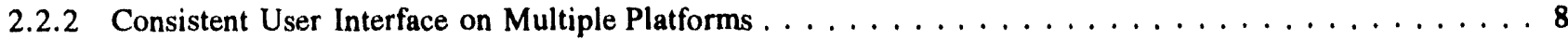

Appendix A

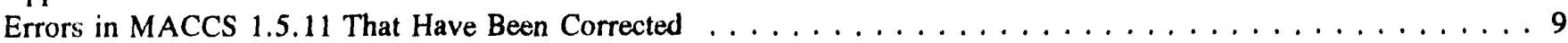

Appendix B

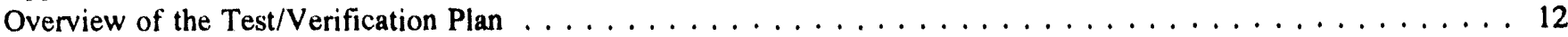

Appendix C

Listing of File README.1ST From Installation Disk \#1

Appendix D

Installation of MACCS on VAX and UNIX Systems .

Appendix E

Installation of MACCS in an Update Program Library . . . . . . . . . . . . . . . . . . . . . . 29

References

30

\section{Tables}

2.1 Implementation of LMF-132 Equations (2.3) and (2.4) in the EARLY User Input File ............. 4

2.2 Comparison of Tissue Weighting Factors From ICRP 26 and ICRP $60 \ldots \ldots$

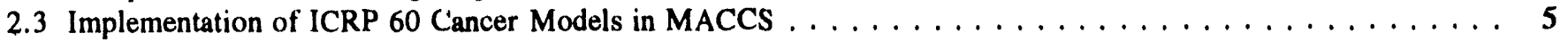

2.4 Number of Cases of Cancer Fatality $(0-1609 \mathrm{~km}) \ldots \ldots \ldots \ldots$

2.5 Population-Weighted Risk of Cancer Fatality $(0-16.1 \mathrm{~km}) \ldots \ldots \ldots$

A.1 MACCS 1.5.11 List Output File Excerpt Showing CHRONC Organ List and Cancer Organ List $\ldots \ldots \ldots \ldots \ldots \ldots$

B.1 Summary of the Assigned Number of Each Verification and the MACCS Input File Used $\ldots \ldots \ldots \ldots \ldots$

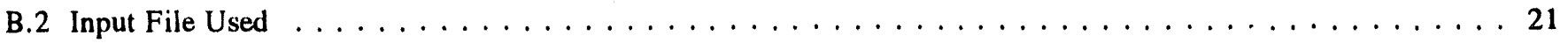

D.1 Largest Numeric Discrepancies for Problem A Run Under UNICOS . . . . . . . . . . . . . . . . 28 


\section{ACKNOWLEDGMENTS}

The development of MACCS has benefitted greatly as a result of comments from its users. The authors extend their appreciation to the many individuals who have provided such feedback during the code's development. For reporting coding errors that are now corrected in the current version, thanks are offered to Chuck Dobbe (Idaho National Engineering Laboratory), Aldo Fanfarillo (ENEL, Rome) Jacques Grupa (General Electric, San Jose), Sue Mlynarczyk (Scientech, Rockville), Lev Neymotin (Brookhaven National Laboratory), and Louis Restrepo (Sandia National Laboratories). The preparation of this report was assisted by the thorough reviews of Jeremy Sprung and Louis Restrepo and the ever-patient word-processing support of Darla Tyree and Judy Jones (all of Sandia National Laboratories). Finally, Christiana Lui of the U.S. Nuclear Regulatory Commission is owed many thanks for her insightful guidance as Project Manager of this effort. 


\subsection{INTRODUCTION}

Subsequent to the release of MACCS 1.5.11 to the government code centers in 1990, the code's capabilities have been enhanced in regard to: (1) accommodating recently published cancer risk coefficients, (2) portability to different types of computers, and (3) ease of maintaining the code on multiple computer platforms. All of these enhancements are described in this report, which is intended as a supplement to the code's published documentation |Ch90,Jo90, Ro90|. The present version of MACCS is packaged in a form immediately usable on high-end IBM compatihle PCs running DOS, though its installation on other types of systems should be a straightforward matter.

Also, during this period a number of errors in the code have heen identified and corrected.
The code corrections have been grouped into two categories: (1) those which may have a significant impact on calculated results, and (2) those deemed to be of minor importance. All of the errors which have been corrected are listed in Appendix A. The Verification Plan and Verification Report for this new version of the code are presented in Appendix B. A listing of the README files included on the PC distribution diskette is given in Appendix C. A description of the sequence of operations performed to install MACCS on VAX/VMS, IBM RISC S/6000, Sun SPARC, and Cray UNICOS computers is given in Appendix D. Finally, for those recipients who wish to install MACCS in an UPDATE [CD80] style program library, brief guidance is provided in Appendix $\mathrm{E}$. 


\subsection{ENHANCEMENTS TO CODE CAPABILITIES}

The cancer risk factors supplied with the prior version of MACCS (i.e., 1.5.11) were based on the recommendations of BEIR III [NA80] as described by Evans et al. [Ev85, Ev90|. Subsequent to the preparation of MACCS 1.5 in December 1989, a reassessment of dosimetry for Japanese A-bomb survivors and a longer follow-up period have led to widespread recognition that the cancer risk factors in BEIR III may lead to underestimates of cancer risk. Reports by U.S. [NA90] and international organizations [IC91] have recommended an increase in cancer risk coefficients hy a factor of about two to three in comparison to BEIR III. A review of several reports providing new cancer risk factors has been performed. In order to implement the recommendations of these reports, a minor modification of the code's input has been performed. All of the changes relating to the code's cancer model are discussed in Section 2.1.

In urder to facilitate the installation of MACCS on a broad range of computer systems, a number of code modifications have been made. The code no longer relies on "preconnected units" since the FORTRAN 77 standard |AN78| does not require that implementations of FORTRAN offer that capability. References to uninitialized variables have been removed. Explicit SAVE statements are used whenever necessary to preserve storage values between suhprogram references. The only machine dependent routines in the code are those required to force an uhort and obtain the date, time, and CPU clock from the operating system. Those machine dependencies are unavoidable due to the fact that the time and date functions are not defined in the ANSI FORTRAN 77 standard.

MACCS is being maintained in a program library format at Sandia National Lahoratories (SNL) with the Code Maintenance Package (CMP) written by Sam Thompson of SNL |Th85]. CMP is a portable FCRTRAN 77 program which emulates a subset of the functions performed hy the Control Data Corporation UPDATE utility.

If CMP or another UPDATE emulator is available, MACCS recipients may implement the code in a program library hy utilizing the file MACCS.SOR on Disk $\# 2$ of the Distrihution Package. The file MACCS.SOR may he used (1) generate an UPDATE style program library with UPDATE, CMP, UPEML |ME87), or another such utility program. If this is done, the resultant program lihrary may be used 10 generate variants of MACCS for use on different computer systems. Through the use of UPDATE'S *IF DEFINE statements, the FORTRAN source code for a number of different computers can he maintained in parallel in a single program library. For those familiar with UPDATE program libraries, installation of MACCS in that format is summarized in Appendix E.

It is not necessary for users to install MACCS in a program library. Complete FORTRAN compiler input files are included in the distribution package for VAX/VMS, DOS/PC, IBM RISC $S / 6000$, Sun SPARC, and Cray UNICOS systems. In addition to the FORTRAN source, Job Control Language (JCL) files are provided to execute MACCS on all of those systems and the system-specific date, time, and CPU clock routines needed for those systems are included in the program library MACCS.SOR. The sequence of operations which were necessary to install MACCS on these systems at SNL are described in Section 2.2.1 and Appendix D.

With the information supplied on diskette, conversion of MACCS to run on additional types of computer systems should he a straightforward matter provided those systems include an ANSI standard FORTRAN compiler and sufficient memory and disk storage. On a $P C$, installation of MACCS requires $4 \mathrm{MB}$ of RAM and 10-20 $\mathrm{M}^{\text {" }}$ of free disk space. If any difficulties are encountered in mstalling MACCS, please contact the authors for assistance.

The current release of the code does not include the DOSFAC and GCMAX programs which were previously included as part of the MACCS 1.5.11 distribution package for VAX/VMS systems. Those auxiliary programs are not a part of MACCS; they are pre-processor codes which were utilized hy the code developers to prepare input data. The GCMAX program has not heen modified since the previous release of MACCS. The DOSFAC program has heen modified to generate dose conversion factors for seven additional organs: adrenals, hladder wall, kidneys, live'., pancreas, spleen, and thymus. The resultant dose conversion factors for these new organs are included in the dose conversion factor file, DOSDATA.INP, distributed with the code. The additional data was ohtained from the same Oak Ridge National Laboratories datahase as used previously and described in Appendix D of the MACCS Model Description [Jo90|. If either DOSFAC or GCMAX are needed for a particular application, please contact the authors.

\subsection{Revised Cancer Risk Modeling}

Tiwo approuches will he described for implementing revised cancer risk coefficients in MACCS. The first approach 
utilizes information from an NRC sponsored reassessment of cancer health effects models performed by Dr. Ethel Gilhert of Battelle Pacific Northwest Laboratories. The results of that reassessment are described in a report, subsequently referred to as LMF-132, prepared by the Inhalation and Toxicology Research Institute [Ab91]. Implementation of the LMF-132 recommendations is described in Section 2.1.1. Cancer risk factors from LMF-132 are heing utilized in the sample problems being distributed with the present version of MACCS.

A second, alternative approach to cancer modeling is taken directly from the ICRP 60 report [IC91] and described in Section 2.1.2. A comparison of results calculated with both methods is given in Section 2.1.3. Another potential source of cancer risk factors is the BEIR V report itself and that report's recommendations are mentioned hriefly in Section 2.1.2.

The NRC reports to date, which comprise the hasis of the MACCS health effects models, have focused exclusively on low-LET radiation. For accidents at commercial power reactors it is expected that high-L.ET radiation would he a small contrihutor to the impacts. When MACCS is applied to some DOE facilities there is a possibility that high-LET radiation can be a dominant contributor. A discussion of high-LET cancer models is given in Section 2.1.4 to provide guidance in applying MACCS in these situations.

\subsubsection{NRC Sponsored Review of Cancer Models Presented in LMF-132}

In previous NRC sponsored work on cancer health effects models $|E v 85, E v 90|$ it was recommended that the diminished effectiveness of low doses in cancer induction he considered through the use of a "linear-quadratic" dose response function. Two functions were defined for each type of cancer health effect: the first for doses above 1.5 Gray, the second for doses below that threshold. Parameter values $(\alpha$ and $\beta$ ) for these functions were chosen that ensure continuity at the crossover point. Mathematically, those two functions represent risk (R) as a function of dose (D) as follows:

$$
\begin{gathered}
R(D)=\alpha \cdot D \\
R(D)=\alpha \cdot D+\beta \cdot D^{2}
\end{gathered}
$$

In the L.MF-132 review of cancer models, the non-linear dose response function has been replaced with a piecewise linear function that is discontinuous. Again, two equations are defined; the first for high exposures and the second for low exposures. The two equations are as follows:

$$
\begin{gathered}
R(D)=\alpha \cdot D \\
R(D)=\alpha \cdot D / D D R E F
\end{gathered}
$$

The DDREF is defined as a "dose and dose rate reduction factor" which is given a value of two in LMF-132 for central estimates of most cancer types. In contrast, for central estimates of breast and thyroid cancers the DDREF is assigned a value of one in LMF-132. The LMF-132 report states that the DDREF is to be applied "when the total dose is less than 0.2 Gray, and for higher doses when the dose rate is less than 0.1 Gray per hour". It should be noted that this definition of circumstances for application of the DDREF is identical to the guidance given in ICRP 60 .

The new version of the code implements Equations (2.3) and $(2.4)$ in its calculation of cancer health effects which would result from exposures during the emergency phase following the accident. The maximum duration of the emergency phase is one week. Subsequent to the emergency phase (i.e., in the so called "chronic period"), exposures should always he at a dose rate of less than 0.1 Gray per hour and therefore the CHRONC module applies the DDREF for all of the long-term exposure pathways.

Within the emergency phase calculations of cancer risk, the switch hetween a high and low dose-response function is based solely on the committed dose from exposure during that period. There is no consideration of the dose rate of the exposure in the code's determination of whether or not to apply the DDREF.

I. regard to the calculation of "other cancers" LMF-132 suggests that bladder cancer, ovarian cancer, and multiple nyeloma are the dominant contributors to the total risk. The report's guidance in this area is equivocal. In a telephone conversation Gilbert suggested that a bladder dose could be utilized. Parameter values implementing the LMF-132 recommendations in MACCS are shown in Table 2. 1 .

These parameter value: are used in the new sample problems being distributed with MACCS. Apart from the specific changes described in this report the MACCS sample problems from the previous release (version 1.5.11) are essentially unchanged. 
Enhancements

Table 2.1

Implementation of LMF-132 Equations (2.3) and (2.4) in the EARLY User Input File

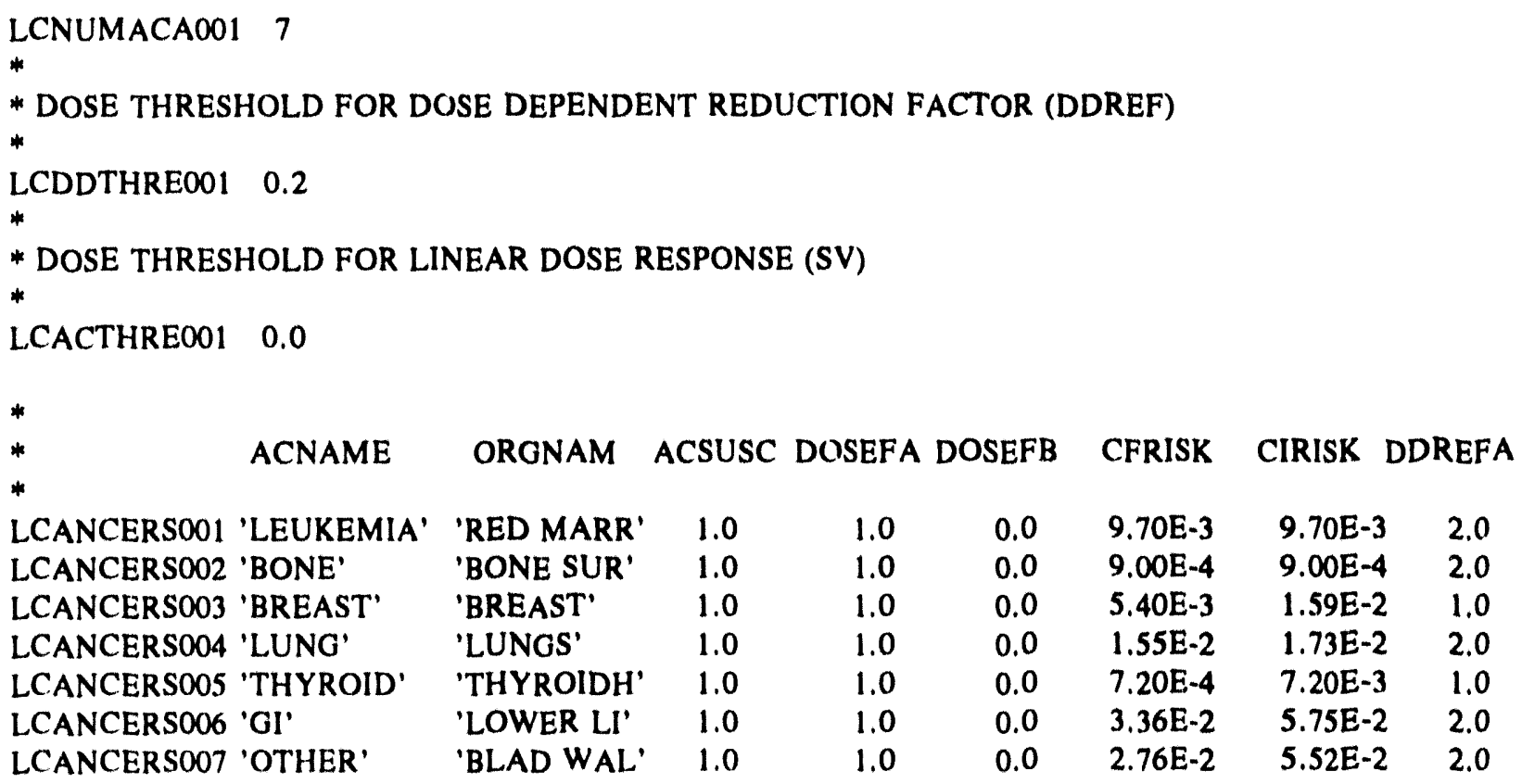

\subsubsection{ICRP 60 Method}

The ICRP has specified cancer risk models appropriate for adult workers as well as the general public. These models are stated in terms of a newly defined radiological unit named "effective dose" [IC91]. The new radiological unit is calculated in the same manner as the "effective dose equivalent" (EDE) defined in ICRP 26 [IC77]. The difference between the two measures results from a change in numerical values used for the organ, or tissue, weighting fractions. The two sets of weighting fractions are compared in Table 2.2 .

For those wishing to utilize ICRP 60 cancer risk factors in MACCS, an example set of MACCS input cards is shown in Table 2.3. At present, the dose conversion factor file provided with MACCS, DOSDATA.INP, does not incorporate any data for the "effective dose" as definerl in ICRP 60. Therefore, in this example, the ICRP 26 "effective dose equivalent" (i.e., EDEWBODY) is utilized.

Despite the change in tissue weighting factors, the ICRP has not called for recalculation of doses made using the ICRP 26 methodology and explicitly states that the two types of dose may be added [IC91]. The MACCS dose conversion factor database includes data for the EDE but the code lacks the capability to calculate the new effective dose measure. Therefore the EDE is recommended as a surrogate for effective dose until dose conversion factors utilizing the ICRP 60 tissue weighting factors are available in MACCS.

For assessing risks to the general public at low exposures, the ICRP recommends a fatal cancer risk factor of 0.05 /sievert and non-fatal cancer risk factor of $0.01 /$ sievert [IC91, p. 22]. This risk factor is recommended by the ICRP "for all equivalent doses resulting from absorbed doses below 0.2 Gray and from higher absorhed doses when the dose rate is less than 0.1 Gray per hour" [IC91,p.19]. For high exposures, that is, those assumed to result in absorbed doses greater than 0.2 Gray and delivered at dose rates greater than 0.1 Gray per hour, the fatality risk factor is doubled to $0.10 /$ sievert effective dose.

As a point of comparison, BEIR $V$ gives a cancer fatality risk factor of 0.008 for an acute dose of 0.1 sievert EDE (i.e., $0.08 /$ sievert) while stating that for low-LET radiation 
Table 2.2

Comparison of Tissue Weighting Factors From ICRP 26 and ICRP 60

\begin{tabular}{lcc}
\multicolumn{1}{c}{ Qrgan } & ICRP 26 & ICRP 60 \\
\cline { 2 - 3 } Gonads & 0.25 & 0.20 \\
Red bone marrow & 0.12 & 0.12 \\
Colon & 0.00 & 0.12 \\
Lungs & 0.12 & 0.12 \\
Stomach & 0.00 & 0.12 \\
Bladder & 0.00 & 0.05 \\
Breasts & 0.15 & 0.05 \\
Liver & 0.00 & 0.05 \\
Oesophagus & 0.00 & 0.05 \\
Thyroid & 0.03 & 0.05 \\
Skin & 0.00 & 0.01 \\
Bone surfaces & 0.03 & 0.01 \\
Remainder & $0.30^{1}$ & $0.05^{2}$
\end{tabular}

ICRP 26 defines "remainder" as the five other organs with the highest dose (e.8., liver, kidney, spleen, thymus, adrenal, pancreas, stomach, small intestine, large intestine, but excluding skin, lens of the eye, and extremities). The weighting factor for each of these organs is 0.06 .

${ }^{2}$ ICRP 60 defines "remainder" as the following: adrenals, brain, upper large intestine, small inteatine, kidney, muscle, pancreas, spleen, thymus, and uterus. The report gives no guidance on how these doses should be combined.

Table 2.3

Implementation of ICRP 60 Cancer Models in MACCS

LCNUMACAOO1 1

*

* DOSE THRESHOLD FOR DOSE DEPENDENT REDUCTION FACTOR (DDREF)

*

LCDDTHRE001 0.2

*

* DOSE THRESHOLD FOR LINEAR DOSE RESPONSE (SV)

*

LCACTHRE001 0.0

*

$*$

LCANCERSO01 'ICRP60' 'EDEWBODY'

ACNAME ORGNAM

ACSUSC DOSEFA DOSEFB CFRISK CIRISK DDREFA

'Extrapolated from ICRP 60, Table 3. 
the same dose over weeks or months would be two times (or more) less effective in inducing cancer (NA90,p.6]. Since BEIR $V$ gives no single estimate of a risk factor to be used for protracted exposures, it is not practical to implement their recommendations in MACCS directly.

If the ICRP 60 approach is used to define a cancer risk model based on a single dose measure, the EDE, the user can achieve a significant savings in computational cost by reducing the number of organs considered in the calculations. However, as is shown later, the two models can yield quite different results in the region close to the point of release.

\subsubsection{Comparison of LMF-132 and ICRP 60 Risk Factors}

By modifying the Sample Problem input file IN2A.INP, the impact of implementing the new cancer risk factors was investiguted. Three MACCS runs, all variations on the curient Sample Prohlem A, were performed:

1. Sample Problem A using the cancer risk factor data defined in the MACCS Model Description, Table 6.2 |Jo90|,

2. the LMF-132 risk factors (Table 2.1) were used, and

3. the ICRP 60 risk factors (Table 2.3) were used in conjunction with EDE dose.

As expected, the change in cancer risk factors affected only the TYPEI results for cancer cases and the TYPE8 results for population-weighted cancer risks [NR86]. For source term number 1 of Sample Problem A, a comparison of the overall weighted-sum results for cancer fatalities is shown in Tahle 2.4. The corresponding comparison for population-weighted cancer fatality risks is given in Table 2.5 .

Implementation of the ICRP cancer model allowed the omission of dose calculations for bone surface and hreast and a reduction in the number of output measures reported (due to the use of a single cancer risk factor). As a result of those changes, the calculational time for Sample Problem A on a 486/25 PC was reduced from 3040 to 2350 seconds. It should not be assumed that the two models are equivalent. Tahle 2.5 shows significant differences in the results ohtained.
If every organ of the body received an equal dose, for low doses and dose rates, the ICRP 60 and the LMF-132 predictions of cancer fatality risk are equal. However, with the reactor source term considered in the code's sample problems, irradiation of the various organs is not uniform. Therefore, it is not surprising to see a roughly factor of two in cancer risk for the $0-10$ mile region where the inhalation pathway is quite important since inhalation can result in a highly non-uniform irradiation of the body. In contrast, for total long-term effects in the 0-1609 kilometer region, groundshine hecomes more important than inhalation and thus irradiation of the organs becomes much more uniform.

\subsubsection{Cancer Risk From Combined High-LET and Low-LET}

MACCS calculates its doses in units of dose equivalent (i.e., sieverts). For the internal pathways of inhalation and ingestion, the dose conversion factors supplied with the code do take account of both low-LET and high-LET radiation. Some radionuclides may emit a combination ." low and high-LET radiation. Since equal absorbed doses from the two types of radiation are not thought to cause similar levels of damage, the concept of "radiation weighting factor" [IC91] is used in order to allow a single measure of detriment representing the total damage caused by the various types of radiation.

The MACCS dose conversion factors were generated taking into account three types of particles: photons, electrons, and alpha particles. Radiation dose from neutrons is not considered in MACCS. For photons and electrons, the standard radiation weighting factor of unity was utilized. For alpha particles, the radiation weighting factor depends on the type of dose being calculated.

MACCS calculates two types of dose: "acute" and "lifetime" [Ch90,Jo90]. The acute dose is used solely for calculation of the non-stochastic effects associated with high exposures such as early fatality, prodromal vomiting, etc. The acute dose as defined in MACCS is not utilized in the cancer risk models. The high-LET radiation weighting factor used in MACCS for calculating acute dose is ten. For lifetime dose, that is, the 0-50 year dose commitment which is used in the cancer models, the high-LFT radiation weighting factor is twenty.

ICRP 60 gives a radiation weighting factor of twenty for alpha particles and thus the dose equivalents calculated by MACCS can be used in conjunction with that report's 
recommendations. Furthermore, if the organ-specific risk factors in LMF-132 are used in a calculation where it is

Table 2.4

Number of Cases of Cancer Fatality (0-1609 km)

\begin{tabular}{lccc}
\hline & Mean & 90th & 95th \\
MACCS 1.5.11 Cancer Risk Factors & & & $1.60 \mathrm{E} 4$ \\
LMF-132 Cancer Model from Table 2.1 & $4.96 \mathrm{E} 3$ & $1.16 \mathrm{E} 4$ & $4.10 \mathrm{E} 4$ \\
ICRP Cancer Model from Table 2.3 & $1.26 \mathrm{E} 4$ & $3.05 \mathrm{E} 4$ & $4.95 \mathrm{E} 4$ \\
\hline
\end{tabular}

Table 2.5

Population-Weighted Risk of Cancer Fatality (0-16.1 km)

\begin{tabular}{llll}
\hline & Mean & 90 th & 95 th \\
MACCS 1.5.11 Cancer Risk Factors & $1.70 \mathrm{E}-3$ & $3.29 \mathrm{E}-3$ & $8.04 \mathrm{E}-3$ \\
I.MF-132 Cancer Model from Table 2.1 & $3.08 \mathrm{E}-3$ & $6.60 \mathrm{E}-3$ & $1.39 \mathrm{E}-2$ \\
ICRP Cancer Model from Table 2.3 & $7.03 \mathrm{E}-3$ & $1.48 \mathrm{E}-2$ & $2.98 \mathrm{E}-2$ \\
\hline
\end{tabular}

assumed that all organs receive equal doses at a low dose rate, the resultant cancer risk predictions from the two models (ICRP 60 and LMF-132) will be identical. That is, if the LMF-132 risk factors for each individual organ are summed, the result is $0.05 /$ Gray--numerically identical to the ICRP 60 risk factor for low LET radiation.

\subsection{Enhanced Portability}

MACCS now assigns unit numbers to its input and output files with FORTRAN OPEN statements in the code. The previous version relied on "preconnection" of units [AN78] accomplished through Job Control Language (JCL) instructions. The code no longer uses preconnected units since some computer systems, notably DOS PCs, do not offer the option of preconnecting a unit number to a file.

Upon a return from a subroutine or function, FORTRAN 77 specifies that values in storage locations may become undefined unless there are explicit SAVE statements to indicate that those values should be preserved. Some compilers will automatically preserve those values whether or not it encounters SAVE statements, notably VAX/VMS systems. On systems which do not automatically preserve storage values, a compiler option switch is usually offered which can be used to cause all local variables to be remembered. The current version does not require the use of such compiler switches. In all routines which require them, SAVE statements have been added to the code to perform that function. Hollerith constants in the code have been replaced by constants of type character. Future versions of FORTRAN will omit the Hollerith constant as a data type.

All known instances of references to undefined variables have been corrected. There is thus no need to utilize compiler switches that cause all storage locations to be initialized to zero.

The amount of random access memory (RAM) required by the code has been reduced by using single COMMON blocks for more than one purpose--essentially "reusing" COMMONs. As a result of this change, 3.7 MB of RAM is now required to run the code on an IBM compatible PC. The previous version required 4.3 MB of RAM. 


\subsubsection{Porting MACCS to VAX and UNIX Systems}

MACCS VERSION 1.5.11.1 is being distributed in PKZIP compressed format on two DOS formatted 3.5" floppy disks (1.4 MB) in order to be readily available to users of IBM compatible PCs, IBM RISC S/6000 or Sun SPARC workstations, Cray UNICOS, and VAX/VMS computer systems. The three README files included on the floppy disks are listed in Appendix C. The file README.1ST, on Disk \#1 explains how to get MACCS running on the PC using Disk \#1 alone. The files MACCS.FOR and MACCS.EXE on Disk \#1 ato Lahey FORTRAN source and executable files for DOS PCs.

In order to obtain MACCS source code for VAX/VMS systems or the UNIX systems (Sun SPARC, IBM RISC $S / 6000$, or Cray UNiCOS), the user must decompress the PKZIP file named MAXLIB.ZIP on Disk $\# 2$ as explained in README.1ST. The file README\#2.TXT produced by this decompression provides additional guidance to the user.

The FORTRAN source code (IBM6000.F, SPARC.F, UNICOS.F, or VAXVMS.FOR), as well as the Sample Problem input and output files and the appropriate Job Control Language file (RUNMAXVX.COM or RUNMAXCS.) must then be transported from the $P C$ to the target system.

Appendix D descrites the sequence of operations which were necessary to install MACCS on VAX/VMS, S/6000, SPARC, and UNICOS systems at Sandia National Lahoratories. Since software and hardware configurations can vary from site to site it is possible that modifications of these procedures may be necessary to meet the local conditions. If any difficulties are encountered, please contact the authors for assistance.

All five versions of MACCS were generated using an I'PDATE format program library containing the machinedependent coding required hy the various systems. The file used to generate the program library is included on Disk \#2 as MACCS.LIB. For guidance on setting up a program lihrary please refer to Appendix E.

\subsubsection{Consistent Usei Interface on Multiple Platforms}

The Job Control Language file provided with MACCS allow a consistent method of initiating the code's execution on five different computer systerns. The convention used for defining the code's input files is based on the approach taken with the VAX/VMS version of MACCS 1.5.11 and descr bed in Appendix C of the MACCS User's Guide [Ch90].

MACCS is erecuted by entering a command at the system prompt. Under DOS, this is usually $C:>$. On VAX/VMS systems the system prompt is usually the dollar sign (\$) while under UNIX systems a per cent symbol (\%) may be present. The command entered is the name of the JCL file followed by arguments corresponding to the code's input and output filenames.

The sequence of filenames is defined as follows: (1) ATMOS User Input FIle, (2) EARLY User Input File, (3) CHRONC User Input File, (4) Meteorological Data File, (5) Site Data File, and (6) List Output File. Six arguments must be supplied since no default values are provided. If any arguments are to be omitted, a null argument is specified as double quotation marks (" ").

With the JCL files provided, Sarnple Problem C is executed as follows:

under DOS,

RUNMAXPC IN1C IN2C IN3C " " "TEMPC

under VMS,

RUNMAXVX INIC IN2C IN3C " " " TEMPC

under UNIX,

RUNMAXCS INIC IN2C IN3C "n " TEMPC. 


\section{Appendix A}

\section{Errors in MACCS 1.5.11 That Have Been Corrected}

\section{Introduction}

In some circumstances the errors described in this appendix may have already been encountered by users of the prior version of MACCS. For some applications, these errors may have had little or no effect on the results generated. The two errors of greatest significance are described in Sections A. 1 and A.2. With the information provided, the user can determine whether either of these errors have been encountered and judge the necessity of repeating any past calculations with the new version of the code, MACCS 1.5.11.1, in which the errors have been corrected. The additional errors described in Section A.3 are not expected to have had a major impact on past calculated results--in most cases the code would either encounter a fatal error and terminate execution or produce a negligible numeric discrepancy.

\section{A.1 Early-Chronc Organ List Discrepancy}

As a result of an error report by General Electric [Gr91], it has been discovered that MACCS 1.5 .11 could generate incorrect results if it is used to calculate population doses and centerline doses (TYPE5 and TYPE6 results) to the thyroid in cases where both the EARLY and CHRONC modules are being exercised. Incorrect results could also result if the CHRONC module is requested to generate a breakdown of long-term population dose (TYPE9 results) to the thyroid. This problem is not limited to thyroid dose results--it could also occur for the stomach if the MACCS Sample Problems are modified so that the CHRONC module generates consequence measures for that organ. For the Sample Problem distributed with MACCS 1.5.11, the thyroid and stomach are the only two organs which could cause this problem.

The cause of this problem is that CHRONC did not actually calculate doses for thyroid and stomach since they were not included in its own internal list of organs. The
CHRONC organ list was defined as being composed of (1) the critical organ for relocation (the input variable CRIORG) in addition to (2) the set of organs used for calculating cancers defined in EARLY. In the Sample Problem, neither thyroid nor stomach were defi-ed as cancer organs in EARLY. Thyroid cancer was . "ned using the pseudo-organ THYROIDH, because, \& the calculation of THYROIDH dose, it was assumed that I-131 within the body is one-third as effective in inducing cancer as other sources of radiation [Ev90].

If CHRONC was requested to produce thyroid or stomach consequence measures and these organs were not defined for calculating cancer risks in EARLY, an undetected internal error could have occurred and erroneous results could have been generated. Those erroneous results might occur for consequence measures other than the TYPE5, TYPE6, and TYPE9 results mentioned above (i.e., everything in that run may be incorrect). This is not the fault of the user since the code's documentation does not prohibit against or warn against the usage that produces the error.

There is no need for concern unless CHRONC was requested to generate TYPE5, TYPE6, or TYPE9 results for an organ not found on its internal list of organs. The List Output file includes two tables which show the CHRONC organs and cancer models. An example of this output is illustrated in Table A.1.

The organs for which CHRONC has calculated doses are EDEWBODY, RED MARR, BONE SUR, BREAST, LUNGS, THYROIDH, and LOWER LI. If any other organs were requested in the generation of CHRONC results, the results of that run may be incorrect. 


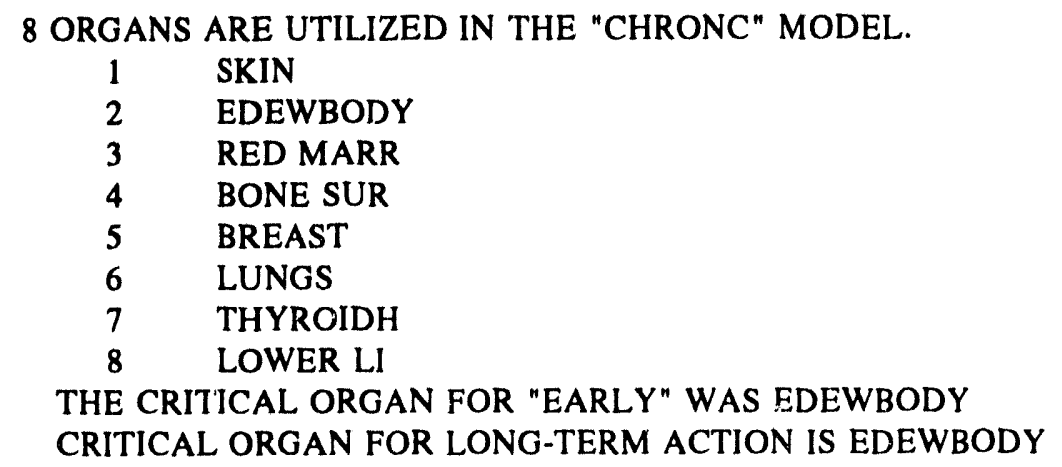

7 CANCER EFFECTS ARE DEFINED IN THE MODEL.

$\begin{array}{cll}\text { INDEX } & \text { CANCER EFFECT } & \text { ORGAN } \\ 1 & \text { LEUKEMIA } & \text { RED MARR } \\ 2 & \text { BONE } & \text { BONE SUR } \\ 3 & \text { BREAST } & \text { BREAST } \\ 4 & \text { LUNG } & \text { LUNGS } \\ 5 & \text { THYROID } & \text { THYROIDH } \\ 6 & \text { GI } & \text { LOWER LI } \\ 7 & \text { OTHER } & \text { LOWER LI } \\ & & \\ \text { A.2 } & \text { Skin Dose Calculated at } \text { Plume } \\ \text { Centerline Height } & \end{array}$

The calculation of dose to the special organ SKIN in MACCS 1.5.11 was incorrectly calculated using the air concentration at the plume centerline height instead of the air concentration at ground level. For ground-level plumes not subject to plume rise this error had no effect. For elevated releases or buoyant plumes, this error could have led to significant overestimation of skin health effects.

\section{A.3 Miscellaneous Minor Corrections}

1. Corrected the failure to initialize error flags and function values in the input processor routines CGET1, IGET1, LGET1, and RGET1.

2. Eliminated the reference to an uninitialized element of array DFING in Suhroutine EXCINP.

\begin{tabular}{ll}
\multicolumn{1}{c}{ ALPHA } & $\ldots$ \\
$3.900 \mathrm{E}-01$ & $\ldots$ \\
$3.900 \mathrm{E}-01$ & $\ldots$ \\
$1.000 \mathrm{E}+00$ & $\ldots$ \\
$3.900 \mathrm{E}-01$ & $\ldots$ \\
$1.000 \mathrm{E}+00$ & $\ldots$ \\
$3.900 \mathrm{E}-01$ & $\ldots$ \\
$3.900 \mathrm{E}-01$ & $\ldots$
\end{tabular}

3. Corrected a failure to initialize Common /MULREL/ in Subroutine INPREL.

4. Improved the code's diagnostic messages when input errors are encountered by Subroutines INPREL, INPOPT, EDCINP, INEVAC, INPOPU, INPEMR, INOUT3.

5. Eliminated a potential divide-by-zero in Subroutine ATMOUT when spatial intervals are large by rewriting the equation for washout to avoid truncation error.

6. Corrected the code's inability to set the risk dominant plume (MAXRIS) to plumes other than the first plume when weather category bin sampling $(M E T C O D=2)$ is being used. The values of IDAY and IHOUR chosen by the weather sampling algorithm are no longer being modified by Subroutine ADJTIM. 
7. Corrected a failure to properly interpret some input character strings--this was reported as an inability to add europium to the list of radionuclides in the ATMOS user input file.

8. In Subroutine EGEOM, developed a new approach to approximating the Gaussian histogram due to failure to achieve exact conservation of mass on deposited material. The table lookup for the error function was replaced with a polynomial tit. Also, the crosswind offset distance is now calculated on the basis of a circular arc instead of the previously used perpendicular tangent distance.

9. In Subroutine LTACUM, when LTACTN $=50$, the last organ on the list was used incorrectly for interpolation of doses to all the organs. Now each individual organ's dose is used for the interpolation instead of using the dose to the last organ on the list.

10. In Subroutine ECCGET, eliminated the doublecounting of evacuation cost in TOTAL ECONOMIC COST

11. The list of organs reported as used by CHRONC on the code's output listing incorrectly included skin. In fact, skin doses are not calculated by CHRONC (in either 1.5.11 or in 1.5.11.1). This error is apparent in Table A.I as produced by MACCS 1.5.11.

12. Corrected a portability problem on the IBM 3090 where due to an apparent error in the IBM FORTRAN implementation, a LOG OF ZERO error is sometimes encountered. The logarithmic inter-polation in Subroutine LTACUM is now performed only if the argument for the log function is at least 1.E-20. In MACCS 1.5.11, the log function is evaluated if the argument is not equal to zero.

13. Corrected a portability problem on the IBM RISC $S / 6000$ where an INTRINSIC function named ABORT was conflicting with a MACCS routine by the same name. To correct the problem, EXTERNAL ABORT statements were added to all the MACCS subprograms which call ABORT. This ensures that the MACCS abort routine will be used to force an exit.

14. Modified the calculation of early fatality and early injury risks to avoid the possibility of numeric overflow when doses are very large.

15. When MACCS is used in the framework of a NUREG-1150 type calculation [NR90] the generation of CCDFs is performed by another program, PRPOST. That program, as well as others in the suite of NUREG-1150 codes, requires that certain information he made available from MACCS. The necessary information can be written to FORTRAN unit 80 as an unformatted file. In addition to writing the unit 80 file, the MACCS result files, units $31-34$, must he preserved after code execution so that they may be processed by the SAVE program. If MACCS is to be used in this manner, the necessary code modifications can be activated by performing a correction run with CMP that includes a *DEFINE, UNIT80 card in the CMP input file. 


\section{APPENDIX B}

\section{B.1 Overview of the Test/Verification Plan}

Several changes have been made to the MACCS code since the release of version 1.5.11. These changes have been made either in an attempt to correct errors that have be $?$ detected in the code since the time of its release or in an attempt to increase the portability of the code if : 0 the PC environment or onto computers other than VAX/VMS. The focus of these changes have been addressed in Appendix $A$ and have been incorporated into revision 1.5.11.1 of the code. The following listing summarizes the diagnosed problems in version 1.5.11 of the MACCS code:

- OPEN statements needed to connect the files to units

- Failure to conserve all material deposited onto the ground

- Failure to properly diagnose user input errors

- Inahility to set MAXRIS to values other than one

- Term in summation of TOTAL ECONOMIC COST omitted

- Potential for divide-hy-zero in ATMOUT

- Code bombs when europium added to the nuclide list

- Incorrect calculation of skin dose at centerline

- Acute/lifetime switch for TYPE 3 results not valiuated

- Improper definition of the CHRONC organ list

- Incorrect organ used in interpolation for LTACTN $=50$

- No switch in EARLY for application of DDREF to cancer risks

- Portahility problems (IBM anil CRAY mainframes and workstations)
- References made to undefined array values in PUTSTM

In an attempt to test/verify the correctness of the changes made to the code a systematic plan has been devised. Verification of the corrections made fall into two categories:

- those that can be tested hy running the code with either (1) altered input files to verify correct handling by the code or (2) creating an auxiliary output file from MACCS which could be visually examined to verify the integrity of corrections made, and

- those that can hest be verified through a visual inspection of the code itself.

\section{B.1.1 Modifications to be Tested by Running the MACCS Code and Inspecting the Output}

It is desirahle to first estahlish some baseline output files which can be used for comparison of results from testing. To do that a hase set of input files is to he created which will used throughout the testing, unless otherwise specified. This hase set of input files will include the following:

- an ATMOS input file which is the Sample Problem A ATMOS input file but without the second source term,

- an EARLY input file which is the Sample Problem A EARLY input, file but with only a single emergency response scenario,

- the Sample Problem A CHRONC input file.

For each general category of test cases, a test identification number (TIN) has heen assigned to each of the general areas in which testing is to be done. When the actual runs are made with the MACCS code a test number will be associated with each run. This test number will carry the designation of (TIN)_\#, where \# is the number of the particular run to test/verify a specific change made to the 
code. This notation will be used in both this appendix and in Appendix C, the test report.

TIN = 1 Failure to conserve all material deposited on the ground

Subroutine(s) modified: EGEOM

An auxiliary output file will be created, and WRITE statements will be inserted into the EGEOM subroutine to produce output which will allow inspection to verify that the material in the tails is in fact being conserved.

Expected result:

It is expected that the material in the tails of the Gaussian distribution is now being conserved by combining it with the material in the outermost elements and that the amount deposited in those elements is being appropriately increased.

$\mathrm{TIN}=2$ Failure to properly diagnose user input errors

Subroutine(s) modified:

CGETI, IGET1, IGETN, LGETN, RGETI RGETN, INPREL, INPOPT, EDCINP, INEVAC, INPOPU, INPEMR,

INOUT3, OPNERL

Test by preparing input files which have the following types of errors:

- incorrect identifiers

- values outside acceptable range for input parameters

- values of incorrect type for input parameters

Expected result:

It is expected that version 1.5.11.1 will give correct and definitive error messages

TIN $=3$ Inability to set MAXRIS to values other than one

Subroutine(s) modified: ADJTIM, BINSAM

Test by running both versions and verify that the code no) longer encounters a fatal execution error when the risk dominant plume is selected to be other than the first plume. Examination of the output should also verify that weather trials are no longer being repeated.

Expected result:

By separating the weather sampling function from the weather loading function the latter will no longer interfere with the former and the weather sampling will function as intended without the code bombing when it encounters an end-of-file during the reading of the weather sampling data.

TIN $=4 \quad$ Term in summation of TOTAL ECONOMIC COST omitted

Subroutine(s) modified: ECCGET

Test by running both versions with the creation of an auxiliary file into which will be written the values of the omitted term and the value of TOTAL ECONOMIC COST to verify that the omitted term is now buing included in the summation.

Expected result:

It is expected that the value of the TOTAL ECONOMIC COST as determined by version 1.5.11.1 will now differ from that of version 1.5 .11 by the value of $\operatorname{ECC}(3)$, the previously omitted term.

TIN $=5 \quad$ Potential for divide-by-zero in ATMOUT

Subroutine(s) modified: ATMOUT

Test by running both versions of the code and setting the following parameter values prior to the calculation of AVGCOV in the subroutine atmout:

DELTIM $=.001$

DISTX1 $=1.0 \mathrm{E}+20$

Expected result:

Version 1.5.11 will homb as it tries a divide by zero, but version 1.5.11.1 will complete the calculation of AVGCOV due the different but equivalent form of the equation used in the calculation.

TIN $=6$ Code bombs when europium is added to the nuclide list

Subroutine(s) modified: IMREAL 


\section{Appendix B}

Test by running both the old and the new versions of MACCS while adding europium to the nuclide list with and without enclosing tics. In addition all other alphabet letters not currently being used as first letters in the nuclide list will be examined to ensure that MACCS doesn't have a yet undetected problem handling another letter.

Expected result:

Both versions are expected to require enclosure by ticks only in the case of the letter $E$ since the problem arose when the code mistook that letter to be a part of a real number. Both versions will require that the letter $E$ be enclosed by ticks, but all other alphabet letters will be properly handled by the code.

TIN $=7 \quad$ Incorrect calculation of skin dose at centerline

Subroutine(s) modified: EPCALC

Test by running both versions of the code and creating an auxiliary file into which the values of HTFCTR and PSF are printed.

Expected result:

It is expected that the values of PSF resulting from the new version will differ from those from the old version by a factor of HTFCTR

TIN $=8 \quad$ Acute/lifetime switch for TYPE 3 results not validated

Subroutine(s) modified: INOUT3

Test by running both versions of MACCS and by using 'NEITHER' as the value of DOSFLG for one of the organs in the early input file.

Expected result:

It is expected that the new version of MACCS will stop execution with an error message that indicates that only 'ACUTE' and 'LIFETIME' art acceptable values for DOSFLG.

TIN $=9$ Incorrect organ used in interpolation for LTACTN $=50$

Subroutine(s) modified: LTACUM
Test by running both versions of the code with LTACTN set to 50 and writing to an auxiliary tile the values of the doses as derived in loops 140 and 160.

Expected result:

It is expected that version 1.5.11.1 will no longer save only the dose for the final organ, but will instead reflect the doses for all organs.

TIN $=10$ No switch in EARLY for application of DDREF to cancer risks

Subroutine(s) modified: INACAN, OPNERL, CANRIS

Test by setting the dose threshold ACTHRE $=10$. and then run the code using a high and low value for the dose dependent reduction factor, i.e., DDREFA $=1$, and then DDREFA $=10$.

Expected result:

It is expected that an order of magnitude difference will be noted in the risk associated with early cancer and injury risks.

TIN $=11$ Portahility problems (IBM and CRAY mainframes and workstations)

Subroutine(s) modified: FATRIS, INJRIS (potential log-ofzero error) PUTSTM (reference to undefined array elements)

Test by running version 1.5.11.1 on the IBM workstation with the Lahey FORTRAN compiler and compare the results to those from running version 1.5.11.1 on the VAX. Also set storage to "undefined" and run both versions on the same IBM workstation. Inspections of the code to verify that the current coding successfully avoids the possibility of trying to take a log-of-zero.

Expected result:

It is expected that the results from the two first two runs will be identical. It is also expected that only version 1.5.11.1 will run when storage is set to "undefined". 


\section{B.1.2 Modification to be Verified Through Inspection of the Code}

The following changes to the MACCS code will be verified through visual inspection of not only the CMP input file but also the coding of version 1.5.11.1 in the MACCS code:

- O:EN statements needed to connect files to
units
Improper definition of the CHRONC organ
list

It is expected that each of the input and output files used during the execution of the MACCS code vill be opened properly. It is further expected that the CHRON: organ list will be found to be a duplication of the EARLY organ list in version 1.5.11.1 of MACCS.

\section{B.2 Verification Report}

Several changes have been made in the MACCS code since the last released version (1.5.11). These changes were made in order to address the issues discussed in Appendix A. To ensure that the changes made have not affected the integrity of the code, the correctness of those changes has been verified by exercising the code and inspecting the output.

For the verification process, a basic set of simplified input files was created. These input files were derived from those for Sample Problem A hy using only a single source term in the ATMOS input file and a single emergency response scenario in the EARLY input file. Both versions of MACCS were then run using the simplified set of input files to establish a haseline output file for each version against which comparisons would be made.

In addition to the changes made to the MACCS code to correct the errors noted in Appendix $A$ or to enhance the portability of the code, there have been rather extensive changes made in the way in which the area under the Gaussian curve is calculated. The original model used linear interpolation based on table lookup values. This has been replaced by a model which uses a formula for the area under the normal distribution from negative infinity to $x$. The formula used was obtained from The Handhook of Mathematical Functions by Ahramovitz and Stegan. The new model affects the calculation of the geometric factors (the average height of the Gaussian over the fine grid elements and the cloudshine correction factors for the fine grid elements) used hy MACCS to determine the early doses. In addition to the changes in the model itself, one of the errors being corrected was to incorporate the material in the tails of the distribution by "dumping" it into the outermost fine grid element. In an attempt to isolate and determine the overall effect of the model change and to isolate and determine the overall effect of the incorporation of the material in the tails of the distribution, version 1.5.11 was run in three configurations:

1. unchanged,

2. replacing the original interpolative model in version 1.5.11 with the new polynomial approximation to the Gaussian curve without including the material in the tails, and

3. using version $1.5,11$ with both the new polynomial approximation (1) the Gaussian curve and incorporating the material in the tails into the outermost elements.

An average increase of $.558 \%$ in the total amount of material deposited when only the interpolative model was replaced hy the polynomial approximation model was calculated. In addition, an average increase of $.542 \%$ in the total amount of material deposited was noted when the material in the tails of the distribution was conserved. As a result of these (wo changes, an overall increase of slightly over $1 \%$ was noted in the deposited material. This increase was reflected in the early effects as calculated hy the MACCS code as expected.

For any given segment of the testing, the code was run with:

1. the input files were constructed to specifically check the way the code responded to specific parameter values, or

2. the MACCS code was altered to create an auxiliary output file used to write out the specific calculated values from within MACCS so the correctness of changes could he verified hy examination of the auxiliary output file.

In most cases, hoth the old and the new versions of MACCS were run. When it was necessary to compare the output from the two versions of MACCS, differences in the 
Appendix B

two output files were isolute $\mathrm{J}$ by running DIFFERENCES on the output files.

A listing of all output files (or DIFFERENCES output file for the two output files) from the test runs has been maintained along with the corresponding input files. These files are availahle for inspection. In those cases where WRITE statements were added to the MACCS code itself 10 verify correct derivation of parameter values, an auxiliary output file was created for that information. These auxiliary output files have also heen maintained.

Table B.1 summarizes the assigned number for each verification procedure, the MACCS inpul files which were used for each of the prosedures, and a brief description of the changes made to the code or the input files for each of the verification procedures. The test number is composed of the TIN (see Section B.I) and a number following the underscore ( ) which indicates a particular configuration of either input files or code changes under which the runs were made for that particular test. The input files used are described in Tahle B.2.

\section{B.3 Summary of Findings of Testing/Verification}

By inspection of the output files from the verification procedures as outlined ahove, it was determined that the changes to MACCS have heen implemented correctly. The current version (1.5.11.1) not only incorporates the indicaled corrections, hut has also been enhanced to improve the error messages hy making them more explicit.

Any modifications made to the code to improve portahility have also heen verifiel hy running the current version of the code and comparing the results with those ohtained hy running MACCS on a VAX/VMS system. No differences have heen found in the output file listings. In addition, the current version does alleviate the potential for overflow and divide-hy-zero errors.

As tested, the current version (1.5.11.1) of MACCS appears to be the result of making corrections and enhancing the code in a way which has maintained the integrity of the code. 
Tuhle B.I

Summary of the Assigned Number of Euch Verticiation und the MACCS Input Files Used

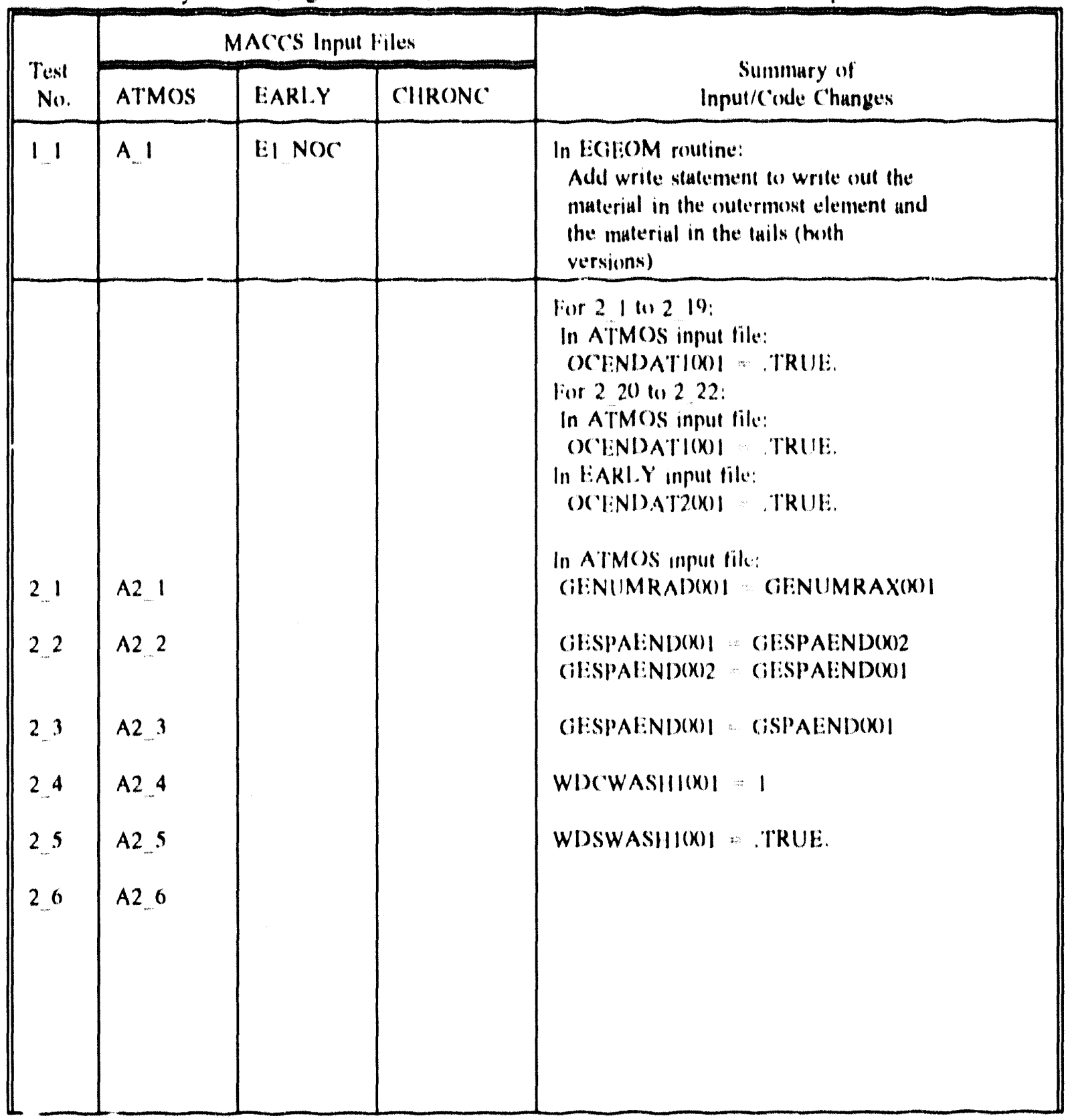


Summary of the Assigned Number of Each Verification and the MACCS Input Files Usod

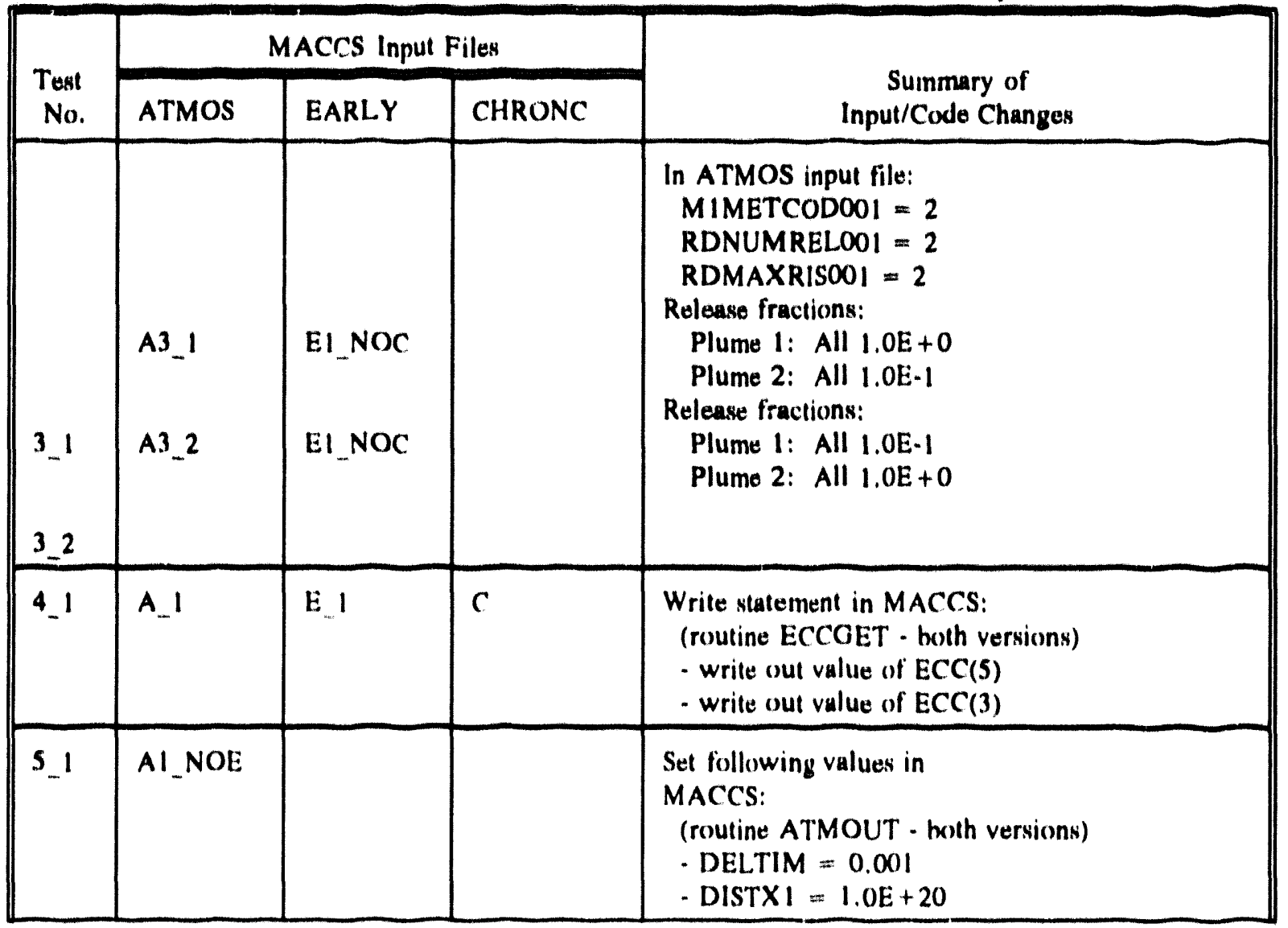


Summary of the Assigned Number of Each Verificution and the MACCS Input Files Used

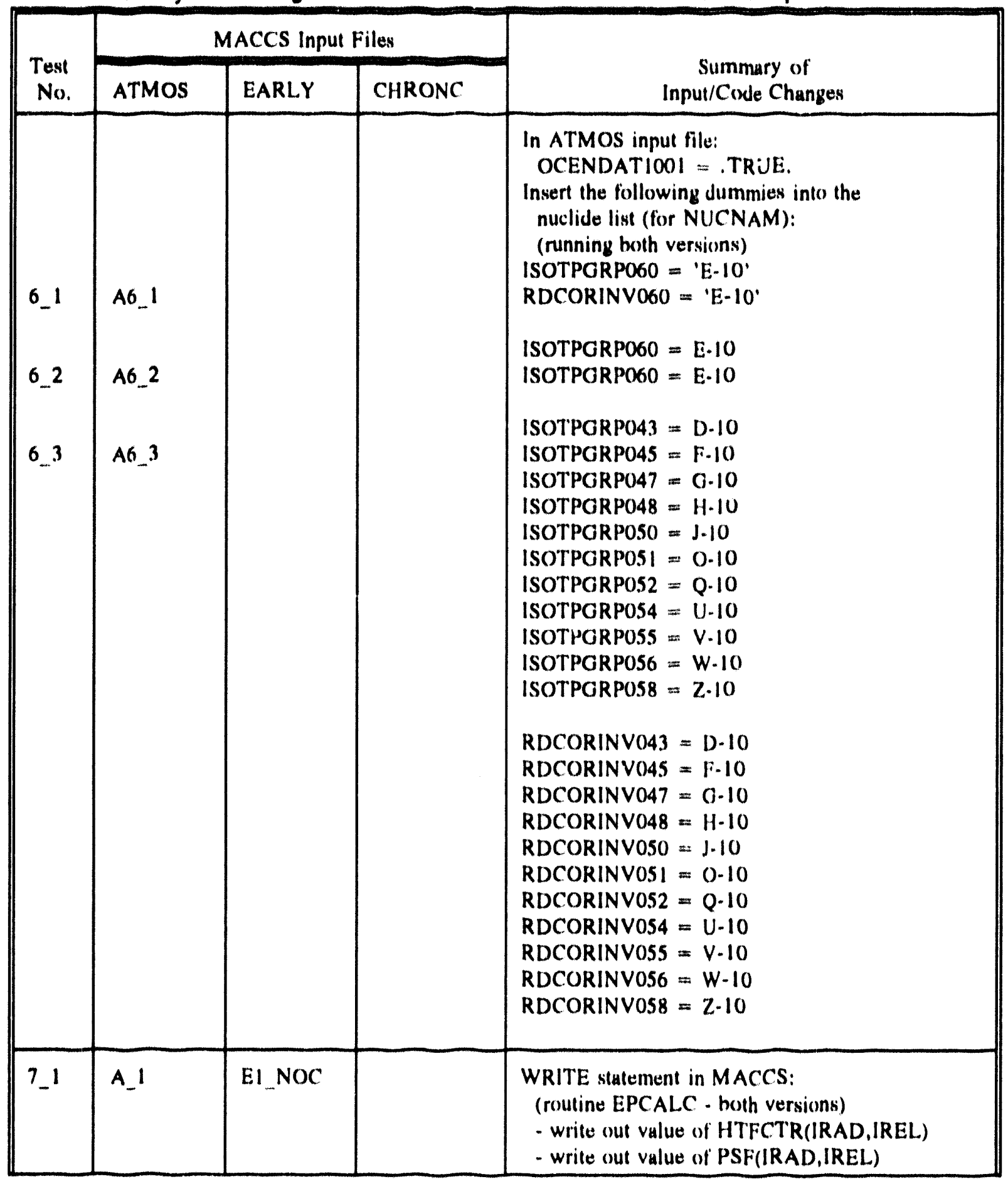


Summary of the Assigned Number of Each Verification and the MACCS Input Files Used

\begin{tabular}{|c|c|c|c|c|}
\hline \multirow{2}{*}{$\begin{array}{l}\text { Test } \\
\text { No. }\end{array}$} & \multicolumn{3}{|c|}{ MACCS Input Files } & \multirow{2}{*}{$\begin{array}{l}\text { Summary of } \\
\text { Input/Code Changes }\end{array}$} \\
\hline & ATMOS & EARLY & CHRONC & \\
\hline 8_i & A_ 1 & E8_1 & & $\begin{array}{l}\text { In ATMOS \& EARLY input files: } \\
\text { OCENDAT1001 = FALSE. } \\
\text { OCENDAT2001 = .TRUE. } \\
\text { In EARLY input file: } \\
\text { TYPE3NUMBEK = } \\
\text { NAME: } \\
\text { TYPE3OUT001 = 'RED MARR' } \\
\text { TYPE3OUT002 }=\text { 'LUNGS' } \\
\text { TYPE3OUT003 }=\text { 'EDEWBODY' } \\
\text { DOSFLG: } \\
\text { TYPE3OUT001 }=\text { 'ACUTE' } \\
\text { TYPE3OUT002 }=\text { 'NEITHER' } \\
\text { TYPE3OUT003 }=\text { 'LIFETIME' }\end{array}$ \\
\hline 9_1 & A_1 & E_1 & c & $\begin{array}{l}\text { Set following value in } \\
\text { MACCS (routine LTACUM): } \\
\text { (run both versions) } \\
\text { LTACTN }=50\end{array}$ \\
\hline $\begin{array}{l}10 \_1 \\
10 \_2\end{array}$ & $\begin{array}{l}A_{-} 1 \\
A_{-} 1\end{array}$ & $\begin{array}{l}\text { E10_1 } \\
\text { E10_2 }\end{array}$ & & $\begin{array}{l}\text { In EARLY input file: } \\
\text { OCENDAT2001 = .TRUE. } \\
\text { In EARLY input file: } \\
\text { (running both versions) } \\
\text { LCACTHRE001 }=10 . \\
\text { DDREFA }=1 . \text { E0 (all) } \\
\text { DDREFA }=1 . \text { EI (all) }\end{array}$ \\
\hline $11 \ldots$ & $A_{-} 1$ & E 1 & $\mathrm{C}$ & $\begin{array}{l}\text { Run both versions on IBM workstation with } \\
\text { Lahey FORTRAN compiler and run both } \\
\text { versions on VAX } \\
\text { Set the following vulue in MACCS (in } \\
\text { routines FATRIS and INJRIS): } \\
\text { (run both versions on IBM workstation } \\
\text { and on VAX) } \\
\text { DRATIO }=1.148\end{array}$ \\
\hline $11 \_2$ & A_1 & E_1 & C & In FATRIS: EFFACB(IFAT) $=100$ \\
\hline 11.3 & $A_{-} 1$ & E_1 & C & $\begin{array}{l}\text { In INJRIS: EIFACB(IFAT) }=100 \text {. } \\
\text { Set storage to "undefined" and run both } \\
\text { versions on a Lahey DOS/PC system }\end{array}$ \\
\hline
\end{tabular}


Table B.2

Input Files Used

\begin{tabular}{|c|c|}
\hline Input File & Description \\
\hline A_l & ATMOS input file using single source term \\
\hline $\begin{array}{l}\text { A2_1 } \\
\text { to } \\
\text { A2_19 } \\
\text { and } \\
\text { A2_21 }\end{array}$ & $\begin{array}{l}\text { ATMOS input files with type mismatch of input variables with the } \\
\text { type expected by MACCS input processing }\end{array}$ \\
\hline $\begin{array}{l}A^{3} \_1 \\
\text { and } \\
A^{3}{ }_{-} 2\end{array}$ & $\begin{array}{l}\text { ATMOS input files to check output when MAXRIS is set to } 2 \text { and } \\
\text { the release fractions are varied between the two plumes in a } \\
\text { consistent manner }\end{array}$ \\
\hline Al_NOE & $\begin{array}{l}\text { ATMOS inpui file with a single source term set to prevent running } \\
\text { the EARLY module }\end{array}$ \\
\hline $\begin{array}{l}A 6 \_1 \\
\text { to } \\
A 6 \_3\end{array}$ & $\begin{array}{l}\text { ATMOS input files set to check the ability of MACCS to read } \\
\text { isotope names beginning with any letter }\end{array}$ \\
\hline E1_NOC & $\begin{array}{l}\text { EARLY input file with a single emergency response scenario and set } \\
\text { to prevent running the CHRONC module }\end{array}$ \\
\hline E_1 & EARLY input file with single emergency response scenario \\
\hline E8_1 & $\begin{array}{l}\text { EARLY input file with single emergency response scenario, set to } \\
\text { prevent running the CHRONC module and to check the ahility of } \\
\text { MACCS to detect errors in input of TYPE3OUT names }\end{array}$ \\
\hline $\begin{array}{l}\text { E10_1 } \\
\text { to } \\
\text { E10_2 }\end{array}$ & $\begin{array}{l}\text { EARLY input files with single emergency response scenario and } \\
\text { setting the variables LCACTHRE and DDREFA to verify that the } \\
\text { dose reduction factor is being correctly applied }\end{array}$ \\
\hline C & Sample problem A CHRONC input file \\
\hline
\end{tabular}




\section{APPENDIX C}

\section{C.1 Listing of File README.1ST From Installation Disk \#1}

Installation of MACCS on a DOS/PC can be accomplished using Disk $\# 1$ alone.

1. Make a directory for the MACCS code MKDIR C:IMAXCOD <CR >

2. Make that directory current

$$
\text { CHDIR C:IMAXCOD }<\text { CR }>
$$

3. Copy floppy disk $\# 1$ to that directory COPY B: ** $* \mathrm{CR}>$

4. Run PKUNZIP to decompress

MAXCOD.ZIP PKUNZIP MAXCOD $<C R>$

5. Follow the directions given in README\#I.TXT

Disk $\#$ I contains all the files needed to install MACCS on an IBM compatible PC and execute the three Sample Problems to verify correct installation.

Disk \#2 contains the files needed to install MACCS on VAX/VMS, IBM RISC S/6000, Sun SPARC, and Cray UNICOS computer systems in addition to UPDATE format source input for generating a program library. For code recipients who will be using MACCS only on PCs, it may not he necessary to load Disk $\sharp 2$.

Notes: Decompression of Disk $\# 1$ requires $4.5 \mathrm{MB}$ of disk storage space.

Decompression of Disk $\# 2$ requires $6.7 \mathrm{MB}$ of disk storage space.

PKUNZIP is a copyrighted program designated as shareware.

Further information can be ohtained hy typing

PKUNZIP $/$ ? $<$ CR $>$

\section{C.2 Listing of File README\#1.TXT From Installation Disk \#1}

This file documents the contents of Disk \#I of the MACCS 1.5, 11. I Package.
Disk \#1 contains the files necessary to exercise MACCS Version 1.5.11.1 on a DOS/PC for all three Sample Problems described in the MACCS User's Guide.

The 23 following files are contained in MAXCOD.ZIP on Disk \#1:

DOSDATA.INP

- Dose conversion factor input file

F77L3.EER

F77L3.FIG

INIA.INP

INIB.INP

INIC.INP

IN2A.INP

IN2B.INP

IN2C.INP

IN3A.INP

IN3B.INP

IN3C.INP

LISTA.OUT

LISTB.OUT

LISTC.OUT
- Error message file used by Lahey FORTRAN at runtime

- Configuration file with cornriler switches for Lahey FORTRAN

- ATMOS input for Sample Problem A

- ATMOS input for Sample Problem B

- ATMOS input for Sample Problem C

- EARLY infal for Sample Problem A

- EARLY input for Sample Problem B

- EARLY input for Sample Problem C.

- CHRONC input for Sample Problem A

- CHRONC input for Sample Problem B

- CHRONC input for Sample Problem C

- List output from Sample Problem A

- List output from Sample Problem B

- List output from Sample Problem C 
MACCS.LOG

- Log file of messages from Lahey FORTRAN

MACCS.EXE

- DOS/PC Executable image of MACCS 1.5.11.1

MACCS.FOR

- DOS/PC FORTRAN source code for MACCS 1.5.11.1

MAKEXEC.BAT

- Batch file to compile and link a FORTRAN program

METSUR.INP

- Meteorological data file for Surry

README\#1.TXT - The help file you are now reading

RUNMAXPC.BAT - Batch file to execute MACCS on a DOS/PC system

SURSIT.INP

- Site data file for Surry

Hardware and Software Requirements for MACCS on an IBM PC or Compatible

IBM PC or compatihle with math coprocessor (30386/30387 or 30486 DX), 4 megabytes of RAM, 20 megabytes disk space for permanent and temporary files, Microsoft or IBM (v. 3.3 or later) or Digital Research (v. 6.0 or later) DOS.

For those users wishing to modify MACCS, the Lahey FORTRAN F77L-EM/32 compiler (v. 4.01 or later) is recommended.

\section{$\underline{\text { Directions }}$}

1. If an expanded/extended memory device driver is installed as a TSR, verify that the TSR driver is compliant with the Virtual Control Point Interface (VCPI) standard. Unless the driver is VCPI compliant, it must be unloaded hefore running MACCS. The OS386 system used by Lahey FORTRAN will manage the usage of expanded memory and therefore there is no need for QEMM, etc., though as long as memory managers are VCPI compliant there should be no need to remove them from the system when running MACCS.

It is possible that the next version of Lahey FORTRAN ( $v$. 5.X) will allow MACCS to be executed under IBM OS $/ 2.0$ or WINDOWS 3.1. Current Lahey FORTRAN (v. 4.02) is incompatible with those operating environments. For information on Lahey FORTRAN compatibility, contact Lahey at (702) 831-2500.

Limited testing of MACCS has shown no incompatibilities with DESQview 386.

2. If Lahey FORTRAN F77L-EM/32 is available, recompile MACCS by typing

\section{MAKEXEC MACCS <CR >}

If Lahey FORTRAN is not available, skip this step and use the executable provided (MACCS.EXE). If any problems are encountered, the Lahey FORTRAN compiler must be used to generate a new executable and a symbol table for the Lahey Symbolic OnLine Debugger (SOLD).

3. Run the three Sample Prohlems hy typing

RUNMAXPC INIC IN2C IN3C $\cdots \cdot \cdot$ TEMPC < CR > RUINMAXPC INIB IN2B IN3B METSUR SURSIT TEMPB <CR > RUNMAXPC INIA IN2A IN3A METSUR SURSIT TEMPA $<C R>$

Sample Problem A required the following times on various machines:

$386 / 25 \quad 7300$ seconds

$486 / 25 \quad 3040$ seconds

$486 / 33 \quad 2170-2380$ seconds

4. Compare ihe calculated results to LISTC.OUT, LISTB.OUT, and LISTA.OUT as supplied on Disk $\# 1$. The results should be identical.

Late Note: An early release of Lahey FORTRAN version 5.0 is known to have an error which prevents proper compilation of MACCS. The linker incorrectly reports that the code requires $800 \mathrm{MB}$ of RAM to load. Lahey was informed of this defect in their software. MACCS is

known to compile correctly under Lahey FORTRAN versions 4.01 and 4.02 . 


\section{C.3 Listing of File README\#2.TXT From Installation Disk \#2}

This file documents the contents of Disk $\# 2$ of the MACCS 1.5.11.1 Package.

Disk \#2 contains the additional files needed to install MACCS on DEC VAX/VMS, as well as Sun SPARC, IBM RISC S/6000, and Cray UNICOS UNIX computer systems.

The 9 following files are contained in MAXLIB.ZIP on Disk \#2:

IBM6000.F

MACCS.SOR

OLD_NEW.OUT

README\#2.TXT

RUNMAXCS.

RUNMAXVX.COM

SPARC.F

UNICOS.F

VAXVMS.FOR
- MACCS FORTRAN source code for IBM RISC S/6000 UNIX workstations,

- UPDATE source input file for a MACCS 1.5.11.1 program library,

- VAX/VMS DIFFERENCES listing comparing 1.5 .11 and 1.5.11.1,

- the text file you are now reading,

- C Shell script for MACCS on the IBM, Sun, and Cray UNIX systems,

- Digital Command Language (DCL) file to run MACCS on VAX/VMS,

- MACCS FORTRAN source code for Sun SPARC UNIX workstations,

- MACCS FORTRAN source code for Cray UNICOS UNIX systems,

- MACCS FORTRAN source code for DEC VAX/VMS systems.
The four FORTRAN source code files include the machinedependent code that was necessary to make MACCS operational on those types of computer systems as found at Sandia National Laboratories (SNL). The specific sequence of operations which were necessary to install MACCS on these SNL computers are described in Appendix D of the letter report "Installation Package for MACCS 1.5.11.1" accompanying the code.

MACCS is maintained at $\mathrm{SN}$ using the Code Maintenance Package (CMP)--an UPDATE emulator written by Sam Thompson of SNL. For those who may wish to install the code in a program library format using CMP, UPEML, or any other such UPDATE emulator, this diskette includes the file MACCS.SOR.

For recipients wishing to learn the exact nature of the differences between VAX/VMS versions 1.5 .11 and 1.5.11.1, a VAX/VMS DIFFERENCES listing is given on this diskette as OLD_NEW.OUT. 


\section{APPENDIX D}

\section{Installation of MACCS on VAX and UNIX Systems}

\section{D.1 VAX/VMS Systems}

Compilation of the MACCS code, VAXVMS.FOR, was a straightforward procedure under VMS 5.3. The following commands were used to create the MACCS executable file:

\section{FORTRAN VAXVMS.FOR}

LINK VAXVMS.OBJ

RENAME VAXVMS.EXE MACCS.EXE DELETE VAXVMS.OBJ

Compilation o: a VAX 8700 at Sandia required about 2 minutes of CPU time using VAX FORTRAN V5.3-50 and produced no warnings or error messages.

The Sample Problem files were ported to the VAX System along with the $\mathrm{VAX}$ command procedure, RUNMAXVX.COM, and were run with the commands:

@UUNMAXVX INIA IN2A IN3A METSUR SURSTT TEMPA QRUNMAXVX INIB IN2B IN3B METSUR SURSTT TEMPB @RUNMAXVX INIC IN2C IN3C " " "TEMPC

Note the use of pairs of double quotes as place holders for input files not necessary for that run of MACCS. The user may wish to consider pre-paring batch submission procedures, notably for Problem A, which required 30 minutes of cpu time on the VAX used at Sandia.

Numeric differences between the Sample Problem results in files LISTA.OUT, LISTB.OUT, and LISTC.OUT on the distribution disks and those generated on the VAX were inconsequential. Discrepancies were limited to differences of \pm 1 in the least significant digit for all hut two lines of output from Problem B. For those two, (lines 1960 and 1990), the IBM PC output in LISTB.OU'T included the word "UNIFORM" while the VAX output listed the value $3.58 \mathrm{E}+03$.

\section{D.2 Sun Sparc Station}

Compilation of the FORTRAN code SPARC.F (MACCS) under SunOS Release 4.1.1 required 4-5 minutes of clock time and was accomplished with the commands:

\author{
$077-\mathrm{N} \times 600$ sparc. fmv a.out maccs.exe
}

This command caused the 177 compiler to generate the executahle file a.out directly with no ohject file. The 77 command above produced message lines for each code module compiled as well as warnings, ("Local variable not usted"), for several modules. These messages were ignored. The compiler switch " $-\mathrm{N} \times 600$ " was found to be necessary due to the large size of the MACCS source file. It should further he noted that the Sun F77 library was installed on this Sun System (a SPARC station 2) containing the routines fdate and etime that provide MACCS with date and time information from the operating system.

After executing the UNIX stutements above, MACCS was run using the $C$ shell script, runmaxcs, as follows:

$$
\begin{aligned}
& \text { chmod } 755 \text { runmaxcs } \\
& \text { runmaxcs in } 10 \text { in } 20 \text { in } 3 c^{\text {n" " " }} \\
& \text { tempe }
\end{aligned}
$$

The first line was necessary to change protection codes on runmaxes after migration to the Sun.

The SPARC System produced the warning message:

Warning: the following IEEE floating-point arithmetic exceptions occurred in this program and were never cleared:

Inexact; Underflow;

when MACCS was run. The warning message was ignored since MACCS is known to generate underflow in some of the calculations.

A minor difference encountered when running MACCS on the SPARC Station was that the lines printed to the screen on the VAX (e.g., "ITRIAL = I", etc.) were written to the list output file (tempc in the above example). For Problem A this amounted to 270 lines and left the interactive user with no indication of program progress. The ITRIAL screen messages, and other informative messages as well, are written to unit * within MACCS (i.e., "WRITE(*," ) in order for them to appear on the computer console (or terminal) and not be written to the list 
output file (unit 6). It was found that using unit 96 for the list output file instead of unit 6 corrected this problem and allowed the output from "WRITE(*," to be written to the console. This patch may not be valid on all systems since a description of the observed hehavior could not be found in the Sun documentation.

Numeric results for the three sample problems were compared to the PC results (as for the VAX implementation.) Discrepancies were limited to differences of \pm 1 in the least significant digit except for one line from Problem B with the same differences mentioned in D.1, namely "UNIFORM" versus $3.58 \mathrm{E}+03$.

\section{D.3 IBM Risc S/6000 Workstation}

The file ihm6000.f, as it appeared under UNIX ufter migration to the IBM S/6000 system, was compiled in about 2.5 clock minutes with the command:

\section{xlf ihm6000.f}

which produced line output for each module, as on the SPARC Station. This included two warnings regarding "FUNCTION or ENTRY is not set" which were disregarded. The outp' from the xlf compiler was a file named a.out, which was renamed to maccs.exe with the UNIX command, mv. No compiler options were found io be necessary. This compiation was done at Sandia under the IBM AIX Version 3 operating system with Version I of AIX XL FORTRAN.

When this version of MACCS was run on the Si6000 the results were similar to the SPARC Station. No warnings were displayed at run time hut the "ITRIAL $=1$ " lines were output to the list output file rather than the screen. No attempt was made to correct this problem. Run time for Prohlem A was found to be ahout 33 clock minutes.

IBM's AIX FORTRAN implementation did not print a leading zero for numbers between zero and one printed with an F FORMAT code. This resulted in a large number of spurious differences generated hy the VAX routine DIFF when it was used to compare output files. It should be noted that the AIX FORTRAN documentation states that leading zeroes are printed, hut an on-line installation note indicates otherwise.

Actual numeric differences produced hy the $S / 6000$ system, in comparison to the IBM PC, included only differences of \pm 1 in the least significant digit and seven occurrences where the difference was 2 in this digit. These latter all amounted to a relative error of much less than 1 percent.

\section{D.4 Cray Unicos System}

Initial attempts to compile unicos.f on the SNLL Cray $X$ MP/28 using CFT77 5.0 under UNICOS 6.1.5 yielded segldr warning messages regarding unsatisfied external references to routines CHROUT, CRNRSK, OUTPT8, and OUTPUT. When it was attempted to run the code, a fatal execution error was encountered.

The unsatisfied external reference messages were determined to be the result of errors in the Cray software. The four supposedly missing routines were all present in the compiler input file. The Cray errors were then avoided hy setting a compiler switch to enable three types of run. time error checks: (1) checking that procedure arguments are matched in number and type, (2) checking array bounds, and (3) checking conformance of arrays in array expressions. MACCS was then compiled as follows:

\section{cft77 - Rahc unicos.f}

This resulted in a successful compilation with only 2 warning messages that were ignored. Both messages stated:

An exponentiation was replaced with a multiplication by optimization. This may cause numerical differences.

Compile time was ahout 2 clock minutes. The resultant ohject file, unicos.o, was run through the Cray linker, segldr, by the command:

$$
\text { segldr unicosio to maccs.exe }
$$

The segldr produced a CAUTION message ("Duplicate entry point 'ABORT' was encountered"). That message may be due to the inclusion of a routine named ABORT in the UNICOS FOR'TRAN library of intrinsic functions. The caution message was ignored.

MACCS was run with the same C shell script as for the SPARC and S/6000 machines hut "ITRIAL = " lines were here directed to the terminal screen. Cpu time required for Prohlem A was about 13 minutes on the Cray with all three run-time checks enahled. 
Numeric differences between the UNICOS results and the IBM PC output were mostly inconsequential. Problems B and $C$ showed only differences of \pm 1 in the least significant digit and the same two differences (lines 1960 and 1990) of "UNIFORM" vs. $3.58 \mathrm{E}+03$ found for the VAX and SPARC systems. However, Problem A exhibited some additional discrepancies when compared to output from the PC.

The MACCS code, unicos.f, was recompiled using the compiler switch -eu, enabling special rounding for real division, in addition to the -Rabc switch. This change removed several numeric discrepancies between the Cray and PC output files. In fact, the entire MACCS output for Problem $A$ then showed only 21 lines with discrepancies more significant than \pm 1 in the least significant digit.
Thirteen of these discrepancies are slight variations in the least significant digit amounting to relative errors much less than 1 percent. The remaining eight discrepancies were extracted from the differences file and are shown in Table D.1. This table includes six pairs of lines produced by the VAX/VMS utility DIFF which was used to do a line-byline comparison of LISTA.OUT, from the IBM PC, and UCSA.OUT, from the UNICOS Cray. The numeric discrepancies are underlined. 
Table D.1

Largest Numenc Discrepancies for Problem A Run under UNICOS

File UDI7:[JFOSTER]LISTA.OUT; 1

2467 ERL FAT/TOTAL

File UD17:[JFOSTER]UCSA.OUT; 1

2467 ERL FATTTOTAL

$1.6-2.1 \mathrm{KM}$

$0.6561 \quad 2.00 E-02$

$1.78 \mathrm{E}-02$

5.99E-02 NOT-FOUND NOT-FOLND NOT-FOUND

$\underline{9.35 \mathrm{E}}$

$* * * * * * * * * * * * * * * * * * * * * *$

File UD 17:[JEUSTER]LISTA.OUT;1

2475 ERL FAT/TOTAL

$1.6-2.1 \mathrm{KM}$

$0.65612 .00 E-02$

$1.78 E-02 \quad$ 5.49E-02 NOT-FOUND NOT-FOUND NOT-FOUND

6.25E-02 6.68E

2475

$0-2.1 \mathrm{KM}$

$0.2089 \quad 2.84 \mathrm{E}-02 \quad 0.00 \mathrm{E}+\infty \quad 2.46 \mathrm{E}-02$

$1.01 E-01$

6.54E-01 $\because$ OT-FOUND

8.50E-01

$\underline{3.56 \mathrm{E}}$

File UD17:[JFOSTER]UCSA.OUT; 1

2475 ERL FATTTOTAL

$0-2.1 \mathrm{KM}$

$0.2089 \quad 2.84 \mathrm{E}-02 \quad 0.00 \mathrm{E}+00 \quad 2.46 \mathrm{E}-02$

$1.0 \mathrm{iE}-01$

6.54E-0!

8.37E-01

8.50E-01 $\quad$ 8.38E

File UD 17:[JFOSTER]LISTA.OUT; 1

$2784 \quad 7.00 \mathrm{E}+\infty \quad 2.28 \mathrm{E}$

File UD17:[JFOSTER]UCSA.OUT; 1

$1.98 \mathrm{E}-01$

$7.00 \mathrm{E}+00 \quad 4.08 \mathrm{E}-01$

$7.00 E+\infty \quad 2.66 E-01$

N.A.

N.A.

2784

$7.00 \mathrm{E}+\infty$

$7.00 \mathrm{E}+\infty$

$1.96 E-01 \quad 7.00 E+\infty \quad 4.08 E-01 \quad 7.00 E+\infty \quad 2.66 E-01$

N.A. N.A.

$\stackrel{\infty}{\infty}$

File UD 17:[JFOSTER]LISTA.OUT:1

File UD17:[JFOSTERILISTA OUT:I

5.00E-02 5.34E-02

$5.00 \mathrm{E}-02$

$6.75 E-02$

$5.00 E-01$

4.55E-02

$5.00 E-02 \quad 8.12 E-02$

N.A. N.A.

File UD 17:[JFOSTER]UCSA.OUT;1

3088 5.34E-02

$5.00 \mathrm{E}-02$

$6.34 \mathrm{E}-02$

$5.00 \mathrm{E}-01 \quad 4.55 \mathrm{E}-02$

$5.00 E-02 \quad 8.12 E-02$

N.A.

N.A.

File UD17:[JFOSTER]LISTA.OUT;1

$3095 \quad 8.39 \mathrm{E}-01 \quad 1.44 \mathrm{E}-03$

$3.56 E-03$

N.D.

N.D.

8.50E-01 $\quad 5.54 \mathrm{E}-05$

N.A.

N.A.

File UD17:[JFOSTER]UCSA.OUT; 1

3095 8.39E-01 $\quad 1.44 \mathrm{E}-03$

8.50E-01 8.38E-04

N.D.

N.D.

8.50E-01 S.54E-05

N.A.

N.A.

File UD17:[JFOSTER]LISTA.OUT; 1

3342 EARLY-ACUTE RED MARR > $1.500 \mathrm{SV}$

$\begin{array}{lllllllll}0.0404 & 5.32 \mathrm{E}-02 & 0.00 \mathrm{E}+\infty & 0.00 \mathrm{E}+\infty & 0.00 \mathrm{E}+\infty & 2.26 \mathrm{E}+\infty & \underline{6.45 E}+\infty & 7.14 \mathrm{E}+\infty & 8.48 \mathrm{E}\end{array}$

File UD 17:[JFOSTER]UCSA.OUT;1

3342 EARLY-ACUTE RED MARR > $1.500 \mathrm{SV}$

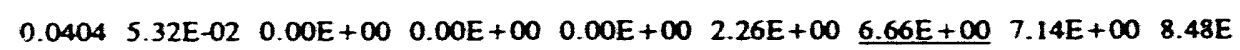




\section{APPENDIX E \\ INSTALLATION OF MACCS IN AN UPDATE PROGRAM LIBRARY}

1. Generate a program library on file MACCS.LIB with an UPDATE creation run by executing the following UPDATE directive:

UPDATE $(\mathrm{l}=$ MACCS.SOR, $\mathrm{N}=$ MACCS.LIB $)$.

2. Construct an UPDATE input file, MACCS.INP, containing *IDENT card and one of the following "DEFINE cards:

"DEFINE, DOS/PC or

*DEFINE, VAX/VMS or

*DEFINE, S/6000 or

*DEFINE, SPARC or

*DEFINE, UNICOS, (depending on which machine is being used.

3. Perform an UPDATE correction run to generate MACCS.FOR as follows:

UPDATE (F, I = MACCS. INP, P = MACCS. LAB, C - MACCS. FOR, DW $=$ 80) 


\section{References}

|Ab911 Ahrahamson, S. et. al., Health Effecis Models for Nuclear Power Plant Accident Consequence Analysiss Modifications of Models Resulting From Recent Reports of Health Effects of lonizine Radiation. Low LET Badiation. Part Il: Scientific Bases for Health Effects Models, Inhulation Toxicology Research Institute, Alhuquerque, NM, NUREG/CR-4214, Rev. I, Purt II, Addendum I, LMF-132,., August 1991.

|AN781 American National Standards Institute, Programming Languave FORTRAN, ANSI X3.9.1978, ISO 1539. 1980(E), New York, NY, 1978.

|CD80] Control Data Corporation, UPDATE Yersion L Reference Manual, 6049900, Revision C, Sunnyvale, CA, Octoher 31, 1980.

[Ch90] Chanin, D. I., et al., MELCUR Accident Consequence Code System (MACCS). User's Quids, Sundia Nutional Lahorutories, Alhuquerque, NM, NUREG/CR-4691, SAND86-1562, Vol. I, Fehruary 1990.

[Ev85] Evans, J. S., et al. Health Effects Model for Nuclear Power Plant Accident Consequence Analysis. Parts Land ll. Harvard School of Puhlic Health. Boston, MA. NUREG/CR-4214, SAND85-7185, July 1985.

[Ev90) Evans, J. S., Letelth Effects Model for Nuclear Power Plane Accident Consecluence Analysis, Low LET Radiation. Pan li Introduction. Intesaration. and Summary. Harvard University, Boston, MA, NUREG/CR-4214, SAND85-7185, Rev. I, Part I, January 1990.

|Grol| Grupa, J., General Electric Co., San Jose, CA, memo to D. Chanin, Sundia National laboratories, Alhuquerque, NM, "Prohlems With MACCS Output", memo dated December 18, 1991.

|IC771 International Commission on Radiological Protection, Annals of the ICRP. Vol. I, No. 3, ICRP Publicution 26. Recommendations of the International Commission on Radiological Protection. Pergamon Press, Oxford, Englanci, 1977.

IIC911 International Commission on Radioligical Protection. Annals of the ICRP, Vol, 21, No. 1-3, ICRP Publication 60, 1990 Recommendations of the International Commission on Radiological Protection, Pergumon Press, Oxford, England, 1991.

[Jo90) Jow, H.-N., et al., MELCOR Accident Consequence Code System (MACCS). Model Description, Sandia National Lahoratories, Alhuquerque, NM, NUREG/('R-4691, SAND86-1562. Fetruary 1990.

[MeR7] Melhorn, T. A., and Young, M. F., UPEML Version 2,0: A Machine-Portable CDC Undate Emulator. Sandia National I dhorutories, Alhuquerque, NM, SAND87-(6679, August 1987.

INA80) National Academy of Sciences, The Effocts on Populations of Exposures to Low Levels of lonizing Kadiation, BEIR III, National Acidemy Press, Washington, DC, 1980.

INA90| National Academy of Sciences, Healih Effects of Exposure to Low Levels of lonizing Radiation, BEIR V. National Academy Press, Washington, DC, 1990.

INR86] U.S. Nuclear Regulatory Commission, "Safety Goals for the Operation of Nuclear Power Plants: Policy Statement", Euderal Register, Vol, 51, No. 149, Washington, DC, August 4, 1986.

[NR90) U.S. Nuclear Regulatory Commission, Severe Accident Risks: An Assessment for Five U.S. Nuclear Power Plants, Washington, DC, NUREG-1150, Decemher 1990. 
[Ro90] Rollstin, J. A., ot al., MELCOR Accident Consequence Code System (MACCS). Prournmmer's Reference Mnnual, Sandia National Lahoratories, Alhuquerque, NM, NUREO/CR-4691, SAND86-1562, Vol. 3, Fehruary 1990.

[Th85] Thompson, S. L., CMP. Code Mnintenance Pucknoe Reference Manual Version 2.0 Sandia National Laboratories, Alhuquerque, NM, SAND85-0825, March 1985. 


\section{Distribution}

Ouk Ridge Nutional Laboratory (2)

Altn: Stove Fisher

Sherrel Greene

MS-8057

P.O. Box $20 \times 99$

Ouk Ridge, TN 37831

Westinghouse Suvannah River Company (2)

Alln: Kevin O'Kula

Jackio East

Sufely Technolugy Section

1991 S. Centennial Ave., Bldg. I

Aiken, SC 29803

Vern Peterson

Building T886B

EO \& O Rocky Fluis

P.O. Box 464

Golden, $\mathrm{CO} 80402$

Brocokhuven Nutional Luborutory (3)

Altn: Lev Neymotin

Arthur Tingle

Trevor Prull

Building 130

Uplon. NY 11973

ECidci Idaho, Inc, (2)

Attn: Doug Brownson

Durrel Knudson

MS-2508

P.O. Bux 1025

IJuho Fulls, ID 8.341 .5

Ecise(i, Idaho Inc. (2)

Altn: Art Roosd

Mike Ahbull

MS-2110

P.O. Bux 1625

Iduho Falls, ID 8.341 .5

Judy Rollstin

G.sAM Ino

85(x) Munual Blva. NE

Alhuyuerque, NM 87112
Los Alumos National Laboratory (2)

Attn: Desmond Stuck

Kent Sextr,

$N-6, K-557$

Los Alamos, NM 87545

Technadyne Engineering Consultants (3)

Altn: David Ch.unin

Joffery Fostor

Walt Murfin

Suito A225

8500 Menual Blvd. NE

Alhuquerque, NM 87112

David M. Brown

Paul C. Rizzo Asscciales, Inc.

300 Oxford Drivo

Monficuille, PA 15146.2347

Wextinghouse Eleciric Company (3)

Altn: John lacoovino

Burt Morris

Griff Holmex

Energy Center Eust, Bldy, 371

P.O. Box 355

Pittshurgh, PA 15230

Murc Rothschild

Hiallihurton NUS

1303 S. Central Ave.

Suite 202

Kent, WA 980.32

Knolls Alomic Power Luhortory (2)

Altn: Ken McDonough

Dominic Sciaudone

Box 1072

Schenectady, NY 12301

Mr. Dennis Strenge

Pacific Northwest Luboratory

RTO//2.5

P.O. Box 999

Rıchland, WA 99352 
Mr. Fred Mann

Westinghouse Hanford Co.

W/A.53

P.O. Box 1970

Richland, WA 99352

Chuck Dobbe

EO \& O liuho

Technical Support Annex

1580 Sawtelle

Iduho Falls, ID 8.3402

Michael McKay

Los Alamos National Lohoratory

A-1, MS F600

P.O. Box 1663

Los Alamos, NM 87544

Sarhen Achurya

Depurtment of Energy

NS-1/FORS

Washington, DC 20585

Lawrence Livermore National Lab. (4)

Altn: George Groenly

Marvin Dickerson

Rolf Lange

Sandra Brereton

Livermore, CA 94550

Mr. Terry Foppe

Sufoly Anulysis Engineoring

Rocky Flats Plant

Energy Systems Group

Rockwell International Corp

P.O. Box 464

Golden. CO 80401

U.S. Environmental Protection Agency (2)

Attn: Allen Richardson Joe Logsdon

Office of Radiution Programs

Environmental Analysis Division

Washington, DC 20460

U.S. Dupartment of Energy (2)

Altn: Kon Murphy (EH35I)

Ed Branagan (EH332)

Washington, DC 20545
Kamiar Jamili

DP-62/FTN

Department of Energy

Washington, D.C. 20585

Mr. Robert Ostmeyer

U.S. Department of Energy

Rocky Flats Areu Office

P.O. Box 928

Golden, CO 80402

Mr. Bruce Burnett

CDRH (HFZ-60)

U.S. Department of Hoalth and Human Services

Food and Drug Administration

5600 Fishers Lane

Rockville, MD 20857

Mr. Scoll Bigelow

S-CUBED

2501 Yale SE, Suite 300

Alhuquerque, NM 87106

David Black

American Electric Power

I Riverside Plaza

Columbus, $\mathrm{OH} 43215$

Gerald Davidson

Fauske and Asscciates, Inc.

16 W 070 Wast 83.3 Streel

Burr Ridge, IL. 60521

Keith Wexolard

Pickard, Lower, and Garrick

Suile 730

1615 M. Street

Washington, DC 20056

Jim Mayberry

Ehasco Services

160 Chubb Ave.

Lyndhurst, NJ 07071

Mr. Mike Cheok

NUS

910 Clopper Roud

Gaithershurg, MD 20878 
Distribution

Ken O'Brien

University of Wisconsin

Nuclear Engineering Dept.

153 Enginoering Research Blvd.

Madison, WI 53706

Mr. Harold Careway

General Electric Co., M/C 754

175 Curtner Ave.

San Jose, CA 95129

Zen Mendoza

SAIC

5150 El Camino Real

Suite (3)

Los Altos, CA 94022

Roger Blond

SAIC

20030 Century Blvd.

Suite 201

Germantown, MD 20874

John Luke

Florida Power \& Light

P.O. Box 14000

Juno Beach, FL 33408

Duke Power Co. (2)

Altn: Duncan Brewer Sleve Deskevich

422 South Church Strett

Charlotle, NC 28242

Mr. Griff Holmes

Westinghouse Electric Co.

Energy Center East

Bldy. 371

P.O. Box 35.5

Pittshurgh, PA 15230

Mr. Edward Warman

Stone \& Wehster Engineering Corp.

P.O. Box 2325

Boston, MA 02107

Mr. William Hopkins

Bechtel Power Corporation

15740 Shady Grove Rond

Gaithershury, MD 20877
R. Troossi

Physical Research, Inc.

25500 Hawthom Blvd.

Torrance, CA 90505

Bill Eakin

Northenst Utilities

Box 270

Hartford, CT 06141

Ian Wall

Eloctric Power Reseurch Instituto

3412 Hillview Avenue

Palo Alto, CA 94304

Jim Moyer

Scientech

11821 Parkluwn Dr.

Suito 100

Rockville, MD 20852

Ray N8

NUMARC

1776 Eye St. NW

Suite 300

Washington, DC 20006-2496

Robert Gobel

Clark University

Center for Technology, Environment and

Dovelopment

950 Main St.

Worcester, MA 01610-1477

Ken Keith

TVA

W 20 D 201

400 West Summit Hill

Knoxville, TN 37092

Shengdar Loe

Yanke Atomic Electric Company

580 Main St.

Bolton, MA 01740

Paul Govaerts

Studiecentrum voor Kernenergie (SCK/CEN)

Boerutang, 200

B-2400 Mol

BELGIUM 


\section{S. Daggupaty}

Environment Canada

4905 Dufforin Street

Downsview

Ontario, M3H 5T4

CANADA

Soren Thykier-Nielsen

Riso National Laboratory

Postbox 49

DK-4000 Roskile

DENMARK

Seppo Vuori

Technical Research Centro of Finland

Nuclear Engineering Laboratory

Lonnrotinkatu 37

P.O. Box 169

Sf-00181 Helsinki 18

FINLAND

Daniel Manesse

IPSN

Voite Postale 6

F-92265 Fontenay-auz-Roses CEDEX

FRANCE

John G. Kollas

Institute of Nuclear Technology and

Radiation Protection

N.R.C.P.S. "Domokritos"

P.O. Box 60228

GR-153 10 Aghia Paraskevi

Attiki

GREECE

ENEA/DISP (2)

Attn: Alvaro Valeri

Alfredo Boltino

Via Vitaliano Brancati, 48

00144 Roma EUR

ITALY

Mr. Hidoo Matsuzuru

Tokai Research Establishment

Tokai-mur

Maka-gun

Ibaraki-ken, 319-11

JAPAN
Mr. Jan Van de Steen

KEMA Laboratories

Utrechisasweg, 310

Postbus 9035

NL-6800 ET Arnhem

THE NETHERLANDS

D. Eugenio Gil Lopez

Consejo de Seguridad Nuclear

Callo Justo Dorado, 11

E-28040 Madrid

SPAIN

Lennart Devell

Studsvik Nuclear

Studsvik Energiteknik AB

S-611 82 Nykoping

SWEDEN

Hanspeter Isaak

Abteilung Strahlenschutz

Hauptabteilung fur die Dicherheit

der Kermanlagen (HSK)

CH-5303 Wurenlingen

SWITZERLAND

Ephraim Asculai

Division of Nuclear Safety

Wagramestrasse, 5

P.O. Box 100

A-1400 Wien

AUSTRIA

Ulf Treten

Environmental Physics Section

Institutt for Energiteknikk

Postboks 40

N-2007 Kjeller

NORWAY

M. K. Yeung

University of Hong Kong

Mechanical Engineering Dept.

Polfulam

HONG KONG

Loonel Canelas

New University of Lisbon

Quinta de Torre

2825 Monte do Caparica

PORTUGAL 
Distribution

Stephen Boult

Electrowatt Engineering Services (UK) Lld.

\section{Grandford House}

16 Carfax, Horsham

West. Sussex RH12 IUP

ENGLAND

Nadia Soido Falcao Martins

Comissao Nacional de Energia Nuclear

R General Severianao 90 S/408-1

Rio de Janeiro

BRAZIL

Eli Stern

Israel AEC Licensing Div.

P.O. Box 7061

Tel-Aviv 61070

ISRAEL.

Der-Yu Hsia

Atomic Energy Council

67. Lane 144

Keelung Road, Section 4

Taipei, Taiwan 10772

TAIWAN

Shankaran Nair

Central Electricity Generating Board

Berkeley Nuclear Laboratories

Berkeley

Gloucestershire CL13 9PB

UNITED KINGDOM

Paul Kayser

Division de la Radioprotection

1, Avenue des Archiducs

L-1135 Luxembourg-Belair

LUXEMBOURG

USNRC

Denwood Ross, AEOD

MS-MNBB 3701

Themis Speis, RES

MS-NL/S 007

Brian Sheron, RESiDSR

MS-NL/S 008
Joseph Murphy, RES/DSIR

MS-NL/S 007

Mark Cunningham, RES/PRAB

MS-NL/S 372

Mat Taylor, EDO

MS-17G21

Bill Morris, RES/DRA

MS-NL/S 007

Zoltan Rosztoczy, RES/ARB

MS-NL/S 169

Donald Cool, RES/RPHEB

MS-NL/S 139

Warren Minners, RES/DSIR

MS-NL/S 007

Thomas King, RES/DSR

MS-NL./S 007

William Beckner, NRR/PRAB

MS-10E4

Frank Congel, NRR/DREP

MS-10E2

Charles Willis, NRR/DREP

MS-10E2

Richard Barrett, NRR/PD3-2

MS-13D1

Lemoine Cunningham, NRR/PRPB

MS-10DR

Ashok Thadani, NRR/DST

MS-8E2

William Russell, NRR/ADT

MS-12G18

Stewart Ebneter

RGN II

A. Bert Davis

RGN III 
James Milhoun

RGN IV

John Martin

RGN V

James Glynn, RES/PRAB

MS-NL/S 372

Harold VanderMolen, RES/PRAB

MS-NL/S 372

Christiana Lui (10), RES/PRAB

MS-NL/S 372

Les Lancaster, RES/PRAB

MS-NL/S 372

Chris Ryder, RES/PRAB

MS-NL/S 372

Michael Jamgochia, RES/SAIB

MS-NL/S 324

Leonard Soffer, RES/SAID

MS-NI/S 324

John Ridgely, RES/SAIB

MS-NL/S 324

Shlomo Yaniv, RES/RPHEB

MS-NL/S 139

Robert Kornasiewicz, RES/DE MS-NL./S 007
Joe Levine, NRR/PRPB

MS-10D4

Robert Palla, NRR/PRAB

MS-10E4

Tom McKenna, AEOD/IRB

MS-MNBB 3206

Thomas Martin

Region I

Internal

$\begin{array}{ll}333 & \text { Norm Grandjean } \\ 6400 & \text { N. R. Ortiz } \\ 6413 & \text { L. A. Miller (10) } \\ 6413 & \text { M. L. Young } \\ 6413 & \text { F. T. Harper } \\ 6413 & \text { T. D. Brown } \\ 7141 & \text { Technical Library (5) } \\ 7151 & \text { Technical Publications (1) } \\ 6453 & \text { L. F. Restrepo } \\ 7714 & \text { Hong-Nian Jow } \\ 8523 & \text { Central Technical Files }\end{array}$



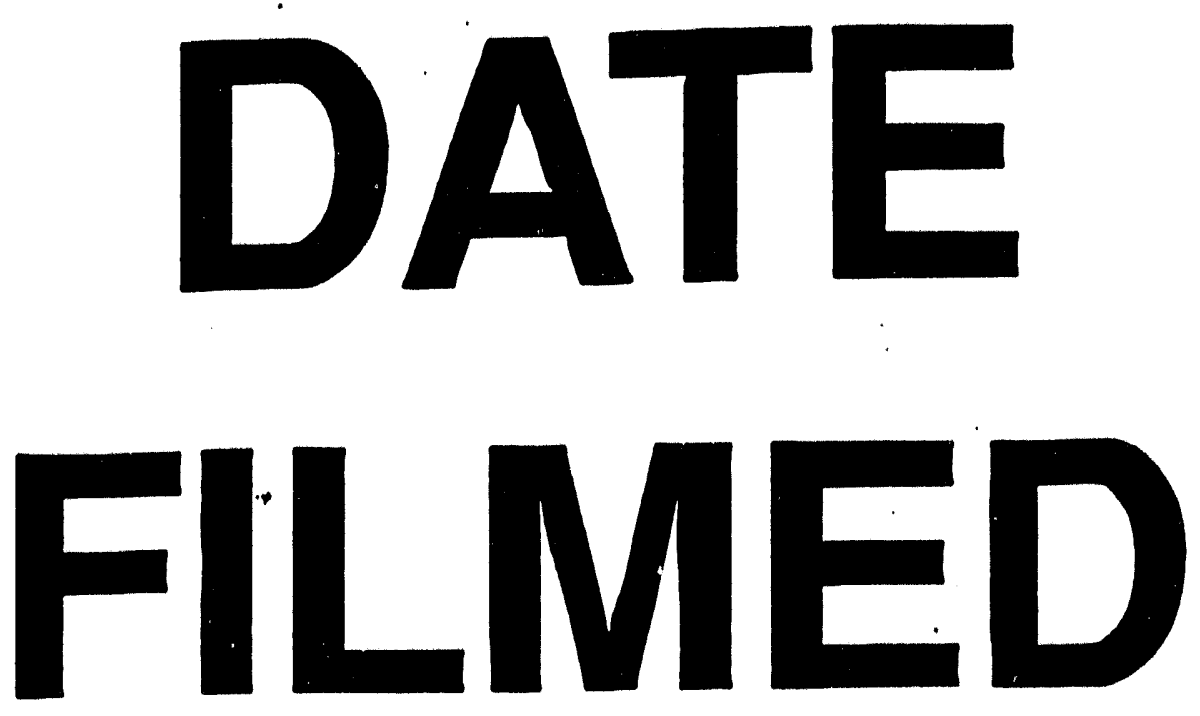

$1 / 6 / 94$
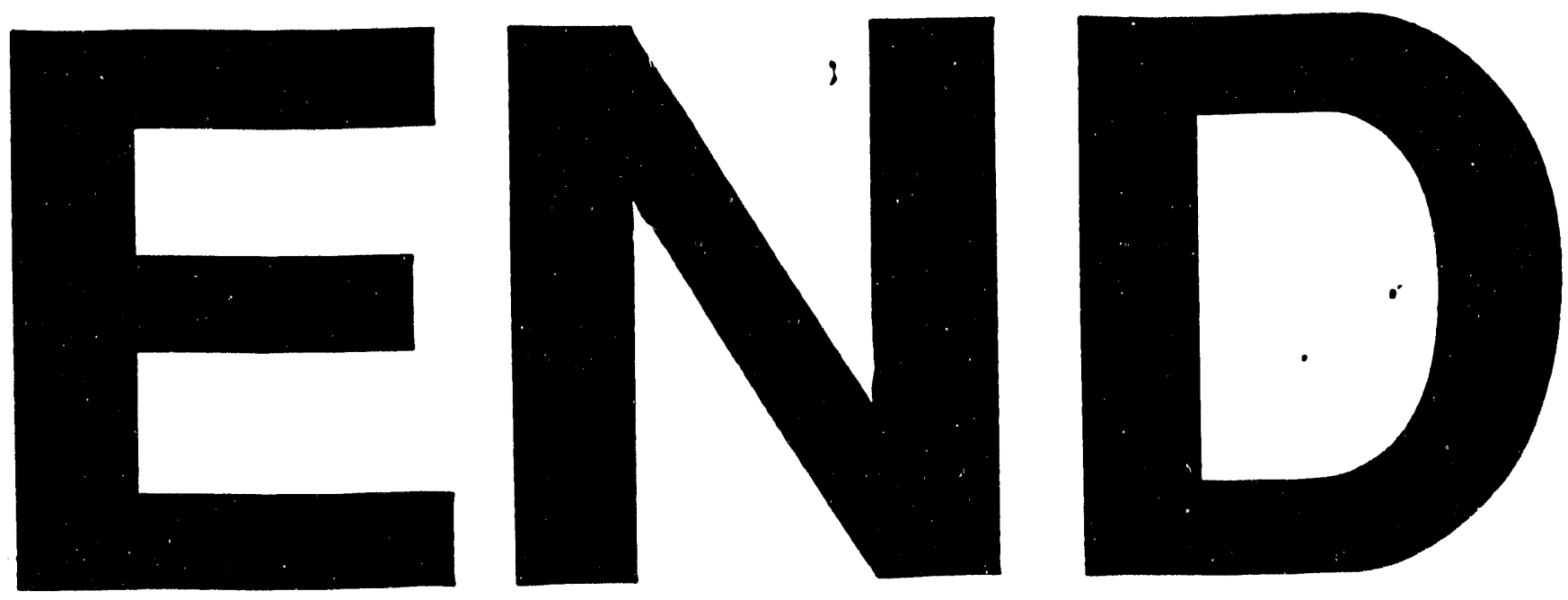


$$
\longrightarrow
$$

